Discourse in Filipino Philosophy

\title{
Si Demeterio at ang Pilosopiyang Pilipino: Pakikipanayam Tungkol sa Kanyang Ika-25 na Taong Pamimilosopiya
}

\author{
Mary Irene Clare O. Deleña \\ Joshua Mariz B. Felicilda \\ Leslie Anne L. Liwanag
}

\begin{abstract}
F.P.A. Demeterio III is one of the leading contributors in the field of Filipino philosophy. He is the author of four books and over 60 articles published in local and international journals. His vast contributions in the said area form a certain pattern of discourse in Filipino philosophy. His first philosophical article was published in 1991, therefore he reached his 25th year of philosophizing last 2016. The authors of this paper returned to his writings and publications in order to design this interview according to Demeterio's classification of Filipino philosophy in 2013. Hence, the research team were able to identify his four major discourses in Filipino philosophy: 1) critical Filipino philosophy, 2) Filipino philosophy as the appropriation of foreign theories, 3) philosophizing using the Filipino language, and 4) exposition of foreign theories. In order to determine the pattern, extent, and depth of his Filipino philosophy in the past 25 years, the authors conducted the interview according to his four salient discourses in Filipino philosophy. This project aims to introduce Demeterio as a significant Filipino philosopher to scholars, students, and those who are interested in the area of Filipino philosophy.
\end{abstract}

Keywords: Demeterio, critical Filipino philosophy, Filipino philosophy and foreign theories, Filipino philosophy and Filipino language 


\section{Introduksyon}

a kasalukuyan, isa sa mga marubdob na tagapagtaguyod ng pilosopiyang Pilipino si F.P.A. Demeterio III ng De La Salle University. Siya ay may apat na libro at mahigit 60 na artikulong nailathala sa iba't ibang lokal at internasyonal na journal. Naglatag ang mga ito ng partikular na hugis ng pilosopiyang Pilipino. Taong 1991 noong unang naglathala ng pilosopikal na artikulo si Demeterio. Samakatuwid, humantong na ang kanyang ika-25 taong pamimilosopiya noong nakaraang taon.

Ilan sa mga higanteng pantas sa larangan ng pilosopiyang Pilipino ang nakapansin na sa mga nagawa ni Demeterio sa nasabing larangan. Sa panayam ni Romualdo Abulad na "Pilosopiyang Pilipino, Uso Pa Ba?"1, sinabing maaaring tingnan bilang babala ang pagkakalipat ni Demeterio at ng mga kasamahan mula sa San Beda College patungong De La Salle University. Senyales ito sa panganib na maaaring umusbong sa paggamit ng araling panlipunan sa pamimilosopiya. May pagkapurista kasi ang pilosopikal na pananaw ni Abulad. Sa panayam ni Rolando Gripaldo na pinamagatang, "Filipino Philosophy: Past and Present," 2 binanggit niya ang 16 na diskurso ng pilosopiyang Pilipinong inilista ni Demeterio sa sanaysay na "Status of and Directions for 'Filipino Philosophy' in Zialcita, Timbreza, Quito, Abulad, Mabaquiao, Gripaldo, and Co." ${ }^{3}$ Sinabi ni Gripaldo na kahalintulad daw ang 16 na diskursong ito sa kanyang tatlong uri ng pilosopiyang Pilipino. Sa sanaysay ni Leonardo Mercado, na pinamagatang "Reflections on the Status of Filipino Philosophy," ${ }^{4}$ naglatag ng isang panukalang direksyon para sa pamimilosopiya ng mga Pilipino batay sa kanyang komentaryo at reaksyon sa dalawang sanaysay ni Demeterio, ang "Status of and Directions for 'Filipino Philosophy' in Zialcita, Timbreza, Quito, Abulad, Mabaquiao, Gripaldo and, Co" at "Assessing the Developmental Potentials of some Twelve Discourses on Filipino Philosophy."5

\footnotetext{
${ }^{1}$ Tingnan ang Romualdo Abulad, “Pilosopiyang Pilipino, Uso Pa Ba?” (Plenary Paper presented at the $10^{\text {th }}$ Philosophical Conference, Sancta Maria Mater et Regina Seminarium, Capiz, Philippines, 2010).

2 Tingnan Ang Rolando Gripaldo, “Filipino Philosophy: Past and Present," (Paper presented at the National Conference of the Philosophical Association of the Philippines, Ateneo de Manila University, Quezon City, 2014).

${ }^{3}$ Tingnan ang F.P.A. Demeterio, "Status of and Directions for 'Filipino Philosophy' in

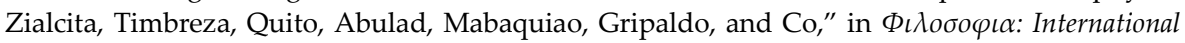
Journal of Philosophy, 14:2 (2013).

${ }^{4}$ Leonardo Mercado, "Reflections on the Status of Filipino Philosophy," in Kritike: An Online Journal of Philosophy, 10:2 (2016), 21-28.

5 Tingnan ang F.P.A. Demeterio, "Assessing the Developmental Potentials of Some Twelve Discourses of Filipino Philosophy," in Philippiniana Sacra, 69:147 (May-August 2014).
}

(C) 2018 Mary Irene Clare O. Deleña, Joshua Mariz B. Felicilda, and Leslie Anne L. Liwanag https://www.kritike.org/journal/issue 22/delena-felicilda-liwanag june2018.pdf 
Bukod sa higanteng pantas na si Gripaldo, may ilang mas nakababatang dalubhasa sa pilosopiyang Pilipino ang nakapansin rin sa mga nagawa ni Demeterio sa parehong larangan. Sa sanaysay ni Rhoderick John Abellanosa na may pamagat na "Local Discourse, Identity and the Search for a Filipino Philosophy: A Re-exploration through the Lens of Reynaldo Ileto," 6 binanggit ang dalawang sanaysay ni Demeterio na "Re-reading Emerita Quito's Thought Concerning the Underdevelopment of Filipino Philosophy"7 at "Thought and Socio-Politics: An Account of the Late Twentieth Century Filipino Philosophy." 8 Kinilala ni Abellanosa bilang isang tagapagtaguyod ng kritikal na pilosopiyang Pilipino si Demeterio. Sa sanaysay ni Franz Cortez na may pamagat na "The Philippine Engagement with Paulo Freire,"9 pinroblematisa niya ang pagiging mailap ng pilosopiyang Pilipino sa mga usaping may kinalaman sa lipunan at politika batay sa diagnosis na ginawa ni Demeterio sa sanaysay na "Thought and Socio-Politics: An Account of the Late Twentieth Century Filipino Philosophy." Sa disertasyon ni Preciosa Regina de Joya na may pamagat na "In Search of Filipino Philosophy,"10 idinetalye rin ni De Joya ang nabanggit nang diagnosis na ginawa ni Demeterio tungkol sa pagiging mailap ng pilosopiyang Pilipino sa mga usaping may kinalaman sa lipunan at politika.

Sa sanaysay ni Emmanuel Batoon na may pamagat na "Tracing Mercado's Anthropological Perspective," 11 tinukoy si Demeterio bilang isa sa mga teorisistang bumatikos sa antropolohikal na pamamamaraan na itinaguyod naman ni Mercado. Kahanay ni Demeterio sa sanaysay na ito sina Emerita Quito, Alfredo Co, Nicanor Abueg, at Andrew Gonzalez. Sa sanaysay ni Roland Theuas Pada na may pamagat na "The Methodological Problems of Filipino Philosophy,"12 inilahad niya ang kritikal na pilosopiyang Pilipino ni Demeterio bilang isa sa mga angkop na solusyon sa

${ }^{6}$ Tingnan ang Rhoderick John Abellanosa, "Local Discourse, Identity and the Search for a Filipino Philosophy: A Re-exploration through the Lens of Reynaldo Ileto," in Asian Perspectives in the Arts and Humanities, 3:1 (2013), 35-59.

7 Tingnan ang F.P.A. Demeterio, “Re-reading Emerita Quito's Thought Concerning the Underdevelopment of Filipino Philosophy," in Scientia: Multidisciplinary Journal of San Beda College (2000).

${ }^{8}$ Tingnan ang F.P.A. Demeterio, "Thought and Socio-Politics: An Account of the Late Twentieth Century Filipino Philosophy," in Hinogwa: The Holy Rosary Seminary Journal, 8:2 (March 2003), 45-73.

9 Tingnan ang Franz Cortez, "The Philippine Engagement with Paulo Freire," in Kritike: An Online Journal of Philosophy, 7:2 (2013), 50-70.

10 Tingnan ang Preciosa Regina De Joya, "In Search of Filipino Philosophy" (Ph.D. Dissertation. National University of Singapore, 2013).

${ }^{11}$ Tingnan ang Emmanuel Batoon, “Tracing Mercado's Anthropological Perspective (Second of Two Parts)," in Kritike: An Online Journal of Philosophy, 8:2 (2014), 1-18.

12 Tingnan ang Roland Theuas Pada, "The Methodological Problems of Filipino Philosophy," in Kritike: An Online Journal of Philosophy, 8:1 (2014), 24-44.

(c) 2018 Mary Irene Clare O. Deleña, Joshua Mariz B. Felicilda, and Leslie Anne L. Liwanag https://www.kritike.org/journal/issue 22/delena-felicilda-liwanag june2018.pdf ISSN 1908-7330

(cc) BY-NC-ND 
mga metodolohikal na problemang bumabagabag sa pilosopiyang Pilipino. Kahilera ng kritikal na pilosopiyang Pilipinong iminungkahi ni Demeterio ang wastong paggamit ng mga antropolohikal na paraan na ipinapamalas naman sa mga obra ni Florentino Hornedo. Sa masteradong tesis ni Rodolfo Bagay, Jr. na may pinamagatang “Development Potentials of Undergraduate Theses in Philosophy,"13 ilang beses na kinasangkapan ang kategorisasyon ng pilosopiyang Pilipino ni Demeterio upang matukoy ang potensyal at kalidad ng kaunlaran ng mga andergradwadong tesis sa pilosopiya mula 2010 hanggang 2013. Sa sanaysay ni Emmanuel De Leon na pinamagatang “Ang Pilosopiya at Pamimilosopiya ni Roque J. Ferriols, SJ: Tungo sa Isang Kritikal na Pamimilosopiyang Filipino,"14 ginamit ni De Leon bilang interpretatibong balangkas ang limang uri ng pilosopiyang Pilipinong inilahad ni Demeterio sa kanyang sanaysay na "Thomism and Filipino Philosophy in the Novels of Rizal: Rethinking the Trajectory of Filipino Thomism." 15

Sa dalawang sanaysay ni Leslie Anne Liwanag na may pamagat na "Ang Pilosopiya ni Sr. Mary John Mananzan, OSB"16 at "Ang Pilosopiya ni Emerita S. Quito," 17 ginamit bilang interpretatibong balangkas ang nabanggit nang 16 na diskurso ng pilosopiyang Pilipino na inilahad ni Demeterio sa sanaysay na "Status of and Directions for 'Filipino Philosophy' in Zialcita, Timbreza, Quito, Abulad, Mabaquiao, Gripaldo, and Co." Sa panayam ni Ben Carlo Atim na may pamagat na "Ang Diskurso ni Feorillo Petronilo Demeterio Tungkol sa Pilosopiyang Filipino: isang Pilosopikal na Pagtatasa," 18 pinuna ang kalakasan at kahinaan ng anyo ng pilosopiyang Pilipinong iminungkahi ni Demeterio. Sa sanaysay ni Jonathan Geronimo na "Ang Karaniwang Filipino bilang Daluyan ng Diskursong Pilosopikal: Panayam kay Dr. Feorillo Petronilo A. Demeterio III,"19 ipinamalas ang

\footnotetext{
${ }^{13}$ Tingnan ang Rodolfo Bagay, Jr., “Development Potentials of Undergraduate Theses in Philosophy" (M.A. Thesis, De La Salle University, 2014).

${ }_{14}$ Tingnan ang Emmanuel De Leon, "Ang Pilosopiya at Pamimilosopiya ni Roque J. Ferriols, SJ: Tungo sa Isang Kritikal na Pamimilosopiyang Filipino," in Kritike: An Online Journal of Philosophy, 9:2 (2015), 28-50.

${ }^{15}$ Tingnan ang F.P.A., Demeterio, "Thomism and Filipino Philosophy in the Novels of Rizal: Rethinking the Trajectory of Filipino Thomism," in Scientia: Multidisciplinary Journal of San Beda College (2005).

16 Tingnan ang Leslie Anne Liwanag, "Ang Pilosopiya ni Sr. Mary Joh Mananzan, OSB," in Kritike: An Online Journal of Philosophy, 9:2 (2015), 51-76.

17 Tingnan ang Leslie Anne Liwanag, "Ang Pilosopiya ni Emerita S. Quito," in Kritike: An Online Journal of Philosophy, 10:1 (2016), 54-82.

18 Ben Carlo Atim, “Ang Diskurso ni Feorillo Petronilo Demeterio Tungkol sa Pilosopiyang Filipino: Isang Pilosopikal na Pagtatasa" (Paper presented at the Second National Conference on Philippine Studies, Caramoan, Camarines Sur, 2016).

19 Jonathan Geronimo, “Ang Karaniwang Filipino bilang Daluyan ng Diskursong Pilosopikal: Panayam kay Dr. Feorillo Petronilo A. Demeterio III," in Hasaan, 3:1 (2016).
}

(C) 2018 Mary Irene Clare O. Deleña, Joshua Mariz B. Felicilda, and Leslie Anne L. Liwanag https://www.kritike.org/journal/issue 22/delena-felicilda-liwanag june2018.pdf 


\section{SI DEMETERIO AT ANG PILOSOPIYANG PILIPINO}

kahalagahan ng wikang pambansa sa larangan ng pagtuturo at pananaliksik sa larangan ng pilosopiya at Araling Filipino sa pamamagitan ng pakikipanayam sa nasabing pantas. Sa disertasyon ni Emmanuel De Leon na "Ang Intelektuwal na Pamana ng mga Pangunahing Tomasinong Pilosoper sa Kasaysayan ng Pamimilosopiyang Filipino: Quito, Mercado, Hornedo, Timbreza, Abulad, at $\mathrm{Co}^{\prime 20}$ nito lamang 2017, napakinabangan ang taksonomiya ng pilosopiyang Pilipino ni Demeterio sa pag-aaral ng mga pangunahing diskurso at kontribusyon ng anim na nangungunang Tomasinong pantas. At sa tesis ni Joshua Felicilda na "Ang mga Politikal na Ideolohiyang Pumapaloob sa mga Nobela ni F. Sionil Jose" 21 nito ring 2017, ginamit ang modipikadong ideyolohikal na spektrum ni Demeterio na halaw mula kay Hans Slomp at unang ginamit sa aklat niyang Ang mga Ideolohiyang Politikal ng Catholic Bishops' Conference of the Philippines. ${ }^{22}$

Layunin ng proyektong itong magagap ang hugis, lawak, at lalim ng pilosopiyang Pilipinong itinataguyod ni Demeterio at maipakilala siya bilang mahalagang pilosopong Pilipino sa mga dalubhasa, mag-aaral, at sinomang may interes sa pilosopiyang Pilipino. Maaaring sabihing handong ang proyektong ito ng kanyang mga naging mag-aaral na tinuruan niyang mamilosopiya mula sa pagsusulat, pananaliksik, at kalaunang paglalathala. Pero bago dumako ang papel sa usapin ng pilosopiya at kaisipan ni Demeterio, mahalagang mabilisang tingnan muna ang kanyang intelektwal na talambuhay para lalong maunawaan ang pilosopiya at kaisipan ng naturang pantas.

\section{Intelektwal na Talambuhay}

Ipinanganak si Demeterio noong 1969 sa maliit at tahimik na lungsod ng Maasin, ang kabisera ng probinsya ng Timog Leyte. Kahit na hindi mayaman ang pamilyang pinanggalingan, sagana naman ito sa kultural at intelektwal na kapital dahil parehong may mga gradwadong degri ang mga magulang at nakapag-aral sa mga pinakamahuhusay na pamantasan sa Metro Manila, Metro Cebu, at maging sa Mindanao. Inumpisahan ni Demeterio ang tersiyaryong pag-aaral noong 1985 sa programang agricultural chemistry sa Visayas State University. Doon nadiskubreng may

20 Emmanuel De Leon, “Ang Intelektuwal na Pamana ng mga Pangunahing Tomasinong Pilosoper sa Kasaysayan ng Pamimilosopiyang Filipino: Quito, Mercado, Hornedo, Timbreza, Abulad, at Co" (Ph.D. Dissertation, University of Santo Tomas, 2017).

${ }^{21}$ Joshua Felicilda, "Ang mga Politikal na Ideolohiyang Pumapaloob sa mga Nobela ni F. Sionil Jose" (M.A. Thesis, De La Salle University, 2017).

${ }^{22}$ F.P.A. Demeterio, Ang mga Ideolohiyang Politikal ng Catholic Bishops' Conference of the Philippines: isang Pag-aaral sa mga Piling Pahayag mula sa Limang Panahon ng Kontemporaryong Eklesiastiko-Politikal na Kasaysayan ng Pilipinas (Manila: De La Salle University Publishing House, 2012)

(c) 2018 Mary Irene Clare O. Deleña, Joshua Mariz B. Felicilda, and Leslie Anne L. Liwanag https://www.kritike.org/journal/issue 22/delena-felicilda-liwanag june2018.pdf ISSN 1908-7330

(c) BY-NC-ND 
kakayahan pala siyang paghusayan ang mga akademikong gawain at may talento sa larangan ng sining. Hindi natapos ang unang napiling programa dahil nagpasya siya noong 1988 na pasukin ang mundo ng pilosopiya at teolohiya sa University of Santo Tomas.

Sa University of Santo Tomas, nakasalamuha niya ang mentor na si Fr. Norberto Castillo, OP, isang Dominikanong pilosopo at kemiko. Si Castillo ang dahilan sa pag-alab ng interes sa hermenyutika pati na ang pagpapahalaga sa katagang "publish or perish." Habang nag-aaral ng teolohiya si Demeterio noong 1991, sabay niyang tinatapos ang masterado sa pilosopiya sa Graduate School ng nasabing unibersidad. Sa Graduate School na ito nag-umpisa ang kanyang interes sa araling Pilipino nang kumuha ng kursong Filipino Psychology sa gabay ni Concepcion Cheng. Ipinabasa sa kanya ni Cheng ang librong Elements of Filipino Philosophy ni Mercado. Subalit tungkol sa kosmolohiya ni Platon pa rin ang isinulat niyang tesis para sa kanyang masterado sa pilosopiya. Nagkataon noong marami siyang mga kaklaseng mga Dominikano sa teolohiya sa University of the Philippines, Diliman na nag-aaral ng iba't ibang graduwadong programa. Habang ipinagpatuloy niya ang pag-aaral ng teolohiya noong 1992, inumpisahan na ni Demeterio ang pag-aaral para sa doktorado sa araling Pilipino sa mga larangan ng pilosopiya, panlipunang sikolohiya at komparatibong panitikan sa University of the Philippines, Diliman. Sa unibersidad na ito, nababad ang kanyang kaisipan sa kritikal na mga teorya ng Frankfurt School, postmodernismo at postkolonyalismo. Lumipas ang 12 taon bago niya natapos ang disertasyon tungkol sa ideolohiya at ilang premyadong nobelang Pilipino na nakasulat sa wikang Ingles.

Taong 1994, nag-umpisang magturo si Demeterio ng pilosopiya sa San Beda College. Dito nakasalamuha niya sina Jose Arcadio Malbarosa, Maxwell Felicilda, at Ramon Rafael Dolor. Sama-sama nilang napagpasyahang ilihis ang direksyon ng pamimilosopiya mula Iskolastisismo at eklektisismo patungo sa kritikal na pamamaraan ng Frankfurt School at postmodernismo. Sa kolehiyo ring ito napatunayan ni Demeterio ang kakayahang mamuno bilang administrador at manggagawa. Noong 2008, sapilitang ipinagretiro sina Demeterio, Malbarosa, Felicilda at Dolor at mabilisang isinara ng mga Benediktinong pari ang buong departamento nang masangkot sa aktibismo ang mga mag-aaral. Sa kabutihang-palad, kinupkop si Demeterio ng Departamento ng Filipino ng De La Salle University na noon ay pinamumunuan ng dati niyang mag-aaral na si Rhoderick Nuncio.

Sa Departamento ng Filipino ng De La Salle University, natutunan ng Ingleserong Bisayang si Demeterio na magsulat gamit ang wikang Filipino. Doon nabigyang-lunas ang kabalintunaan ng kanyang pagiging Ingleserong dalubhasa sa pilosopiyang Pilipino. Nagbigay-daan ang 
kanyang mga sanaysay sa pilosopiyang Pilipinong nakasulat sa wikang Filipino upang mag-ambag sa lumalaking espasyo ng Kritike: An Online Journal of Philosophy-hindi lamang para sa pilosopiyang Pilipino, kundi maging sa mga sanaysay na nakasulat sa wikang pambansa. Lumipas ang limang taon bago niya nakuhang muli ang ranggong full professor na naiwan sa San Beda College. Sa De La Salle University lamang nagkaroon ng pagkakataong makapaglakbay sa iba't ibang bansa si Demeterio. Sa karanasang ito lalong umigting ang kanyang dedikasyon sa araling Pilipino at pilosopiyang Pilipino. Sa pagiging administrador sa larangan ng pananaliksik, natuklasan niya ang halaga ng kolaborasyon kasama ang ilang gradwadong mag-aaral. Kalaunang naging tagapagtaguyod siya ng ideya ng research university na unang kinonseptwalisa ng Alemang pilosopong si Wilhelm von Humboldt. Noong taong 2013, naging visiting research fellow si Demeterio ng Catholic University of America. At noong 2014, ginawaran siya ng outstanding alumnus award ng Graduate School ng University of Santo Tomas para sa naging kontribusyon sa pilosopiya.

\section{Metodolohiya}

Para makamit ang layunin ng proyektong gagapin ang hugis, lawak, at lalim ng pilosopiyang Pilipinong itinataguyod ni Demeterio, may dalawa ngunit magkakaugnay na substantibong seksyon ang papel. Tinukoy ng unang substantibong seksyon ang apat na diskurso ng pilosopiyang Pilipinong higit na pinagtutuunang-pansin ni Demeterio. Naglalaman ng ikalawang substantibong seksyon ng transkrip ng pakikipanayam ng mga mananaliksik kay Demeterio tungkol sa apat na diskurso ng pilosopiyang Pilipinong higit niyang pinagtutuunan ng pansin.

Para sa Unang Substantibong Seksyon: Para matukoy ang apat na diskurso ng pilosopiyang Pilipinong higit na pinagtutuunang-pansin ni Demeterio, binasa muna ng mga mananaliksik ang kanyang mga obra. Ang mga sumusunod ang pamagat ng kanyang mga aklat: 1) Ang mga Ideolohiyang Politikal ng Catholic Bishops' Conference of the Philippines: isang Pag-aaral sa mga Piling Pahayag mula sa Limang Panahon ng Kontemporaryong Eklesiastiko-Politikal na Kasaysayan ng Pilipinas (2012); 2) Ferdinand Blumentritt and the Philippines: Insights and Lessons for Contemporary Philippine Studies (2013); 3) From Exceptionality to Exceptional: Inclusion of Differently-Abled Persons in the Workplace (2014, isinulat kasama sina Roberto Javier, Raymund Habaradas, Melvin Javar, at Ron Resurreccion); at 4) The Socio-Political Discourses of the Catholic Bishops' Conference of the Philippines: An Analysis from the Perspective of Young's Theories of Structural Justice and Collective Responsibility (nasa palimbagan pa lamang). Minabuting hindi muna isali sa kasalukuyang pagaaral ng mga mananaliksik ang pangatlong libro dahil mahirap tukuyin kung

(C) 2018 Mary Irene Clare O. Deleña, Joshua Mariz B. Felicilda, and Leslie Anne L. Liwanag https://www.kritike.org/journal/issue 22/delena-felicilda-liwanag june2018.pdf ISSN 1908-7330

(c) $)$ BY-NC-ND 
alin ang naging ambag ni Demeterio sa kolaborasyong ito. Ipinapakita naman sa Table 1 ang mga artikulong nailathala niya mula 1991 hanggang 2017.

\begin{tabular}{|c|c|c|c|c|}
\hline Bilang & Pamagat & Journal & $\begin{array}{c}\text { Co-Author/ Mga } \\
\text { Co-Author }\end{array}$ & Taon \\
\hline 1 & $\begin{array}{l}\text { The Platonic Undertones } \\
\text { of Modern Physics }\end{array}$ & $\begin{array}{c}\text { The Thomasian } \\
\text { Philosopher }\end{array}$ & Wala & 1991 \\
\hline 2 & $\begin{array}{l}\text { The Structure of Filipino } \\
\text { Morality }\end{array}$ & $\begin{array}{c}\text { The UST Theology } \\
\text { Journal }\end{array}$ & Wala & 1992 \\
\hline 3 & $\begin{array}{l}\text { Semiology on the } \\
\text { Invariable Sacramental } \\
\text { Elements }\end{array}$ & $\begin{array}{c}\text { The UST Theology } \\
\text { Journal }\end{array}$ & Wala & 1993 \\
\hline 4 & $\begin{array}{l}\text { Taking Advantage of } \\
\text { Man's Freedom or } \\
\text { Unfreedom }\end{array}$ & Scientia & Wala & 1996 \\
\hline 5 & $\begin{array}{l}\text { Thesis Writing Guidelines } \\
\text { for the Senior Students of } \\
\text { the Philosophy } \\
\text { Department, SBC-CAS }\end{array}$ & Scientia & Wala & 1997 \\
\hline 6 & $\begin{array}{l}\text { The Genealogy of Filipino } \\
\text { Values }\end{array}$ & Scientia & Wala & 1998 \\
\hline 7 & $\begin{array}{l}\text { The Politics of Knowledge } \\
\text { in the Spanish Colonial } \\
\text { Philippines }\end{array}$ & Scientia & Wala & 1999 \\
\hline 8 & $\begin{array}{l}\text { Re-Reading Emerita } \\
\text { Quito's Thoughts on the } \\
\text { Underdevelopment of } \\
\text { Filipino Philosophy }\end{array}$ & Scientia & Wala & 2000 \\
\hline 9 & $\begin{array}{l}\text { The Rhetorical Profile of } \\
\text { Cebuano Radio Drama }\end{array}$ & Scientia & Wala & 2001 \\
\hline 10 & $\begin{array}{l}\text { Cognitive Anthropology } \\
\text { and the Unfinished } \\
\text { Agenda of the Early } \\
\text { Indigenous Phase of } \\
\text { Filipino Philosophy }\end{array}$ & $\begin{array}{c}\text { The Thomasian } \\
\text { Philosopher }\end{array}$ & Wala & 2001 \\
\hline 11 & $\begin{array}{l}\text { Thought and Socio- } \\
\text { Politics: An Account of } \\
\text { the Late 20 } 0^{\text {th }} \text { Century } \\
\text { Filipino Philosophy }\end{array}$ & Hingowa & Wala & 2002 \\
\hline 12 & $\begin{array}{l}\text { The Aesthetics of } \\
\text { Cebuano Radio Drama }\end{array}$ & Scientia & Wala & 2002 \\
\hline 13 & $\begin{array}{l}\text { Defining the Appropriate } \\
\text { Locus of Radical Peace } \\
\text { Studies in Filipino } \\
\text { Philosophy }\end{array}$ & Philippiniana Sacra & Wala & 2003 \\
\hline 14 & $\begin{array}{l}\text { The Grammar of Social } \\
\text { Conflict in the Philippine } \\
\text { Electoral Process and the } \\
\text { Task of Filipino } \\
\text { Philosophy }\end{array}$ & Philippiniana Sacra & Wala & 2003 \\
\hline
\end{tabular}


106 SI DEMETERIO AT ANG PILOSOPIYANG PILIPINO

\begin{tabular}{|c|c|c|c|c|}
\hline 15 & $\begin{array}{l}\text { Our Premodernity and } \\
\text { their Tokens of } \\
\text { Postmodernity }\end{array}$ & Philosophia & Wala & 2003 \\
\hline 16 & $\begin{array}{l}\text { New Paradigms for a } \\
\text { Thesis Work in Filipino } \\
\text { Philosophy }\end{array}$ & Scientia & Wala & 2003 \\
\hline 17 & $\begin{array}{l}\text { The Image and Symbol of } \\
\text { the Self in the Award- } \\
\text { Winning Filipino Novels } \\
\text { in English }\end{array}$ & Scientia & Wala & 2004 \\
\hline 18 & $\begin{array}{l}\text { Thomism and Filipino } \\
\text { Philosophy in the Novels } \\
\text { of Jose Rizal }\end{array}$ & Scientia & Wala & 2005 \\
\hline 19 & $\begin{array}{l}\text { The Religious Ideology in } \\
\text { the Award-Winning } \\
\text { Filipino Novels in English }\end{array}$ & $\begin{array}{c}\text { The Bedan Research } \\
\text { Journal }\end{array}$ & Wala & 2005 \\
\hline 20 & $\begin{array}{l}\text { A Habermasian Reading } \\
\text { of the Political Philosophy } \\
\text { Contained in the } \\
\text { Encyclical Deus Caritas Est }\end{array}$ & Scientia & Wala & 2006 \\
\hline 21 & $\begin{array}{l}\text { The Philippine Church, } \\
\text { State, and People on the } \\
\text { Problem of Population }\end{array}$ & Kritike & Wala & 2007 \\
\hline 22 & $\begin{array}{l}\text { A Comparative Study on } \\
\text { the Theme of Human } \\
\text { Existence in the Novels of } \\
\text { Camus and Jose }\end{array}$ & Kritike & Wala & 2008 \\
\hline 23 & $\begin{array}{l}\text { Some Useful Lessons from } \\
\text { Richard Rorty's } \\
\text { Pragmatism for Filipino } \\
\text { Postcolonial Discourses }\end{array}$ & Kritike & Wala & 2008 \\
\hline 24 & $\begin{array}{l}\text { Ang Balangkas Ng } \\
\text { Multikulturalismo At Ang } \\
\text { Pagbubuo Ng Bansang } \\
\text { Pilipino }\end{array}$ & Lumina & Wala & 2009 \\
\hline 25 & $\begin{array}{l}\text { Ang mga Teorya ng } \\
\text { Relatividad ni Albert } \\
\text { Einstein: Isang Pagsusuri } \\
\text { sa Kahandaan ng Wikang } \\
\text { Filipino sa Pagtatalakay sa } \\
\text { mga Paksa ng } \\
\text { Makabagong Agham } \\
\end{array}$ & Malay & Wala & 2009 \\
\hline 26 & $\begin{array}{l}\text { Dreaming with a } \\
\text { Hammer: On Critical } \\
\text { Theory in the Philippines } \\
\text { (A Philosophical Fiction) }\end{array}$ & Kritike & Wala & 2009 \\
\hline 27 & $\begin{array}{l}\text { Time Traveler: On Critical } \\
\text { Theory in the Philippines } \\
\text { Part } 2 \text { (A Philosophical } \\
\text { Fiction) }\end{array}$ & Kritike & Wala & 2009 \\
\hline 28 & $\begin{array}{l}\text { Mga Anyo at Antas ng } \\
\text { Pag-asa na Nakapaloob sa }\end{array}$ & Malay & Wala & 2010 \\
\hline
\end{tabular}

(c) 2018 Mary Irene Clare O. Deleña, Joshua Mariz B. Felicilda, and Leslie Anne L. Liwanag https://www.kritike.org/journal/issue 22/delena-felicilda-liwanag june2018.pdf ISSN 1908-7330 


\begin{tabular}{|c|c|c|c|c|}
\hline & $\begin{array}{l}\text { mga Diskurso ng } \\
\text { Kilusang El Shaddai }\end{array}$ & & & \\
\hline 29 & $\begin{array}{l}\text { Ang Demokratikong } \\
\text { Sistema at ang mga } \\
\text { Modelo ng Pamumuno sa } \\
\text { Pilipinas }\end{array}$ & Kritike & Wala & 2010 \\
\hline 30 & $\begin{array}{l}\text { Ang Kautusan ng } \\
\text { Departamento ng } \\
\text { Edukasyon Bilang 74, } \\
\text { Serye 2009: Isang } \\
\text { Pagsusuri sa Katatagan ng } \\
\text { Programang Edukasyon } \\
\text { sa Unang Wika (MLE) ng } \\
\text { Filipinas }\end{array}$ & Malay & Wala & 2010 \\
\hline 31 & $\begin{array}{l}\text { Elixirs and Fabulous } \\
\text { Potions: On Critical } \\
\text { Theory in the Philippines } \\
\text { Part } 3 \text { (A Philosophical } \\
\text { Fiction) }\end{array}$ & Kritike & Wala & 2011 \\
\hline 32 & $\begin{array}{l}\text { Conflict of Aesthetic } \\
\text { Systems: Controversy } \\
\text { about Carlo J. Caparas as } \\
\text { National Artist } \\
\end{array}$ & Philosophia & Wala & 2011 \\
\hline 33 & $\begin{array}{l}\text { Ang Pilosopiya ni } \\
\text { Theodor W. Adorno } \\
\text { bilang Batayang } \\
\text { Teoretikal sa Araling } \\
\text { Pilipino }\end{array}$ & Scientia & Wala & 2011 \\
\hline 34 & $\begin{array}{l}\text { Ang Kallipolis at ang } \\
\text { Ating Kasalukuyang } \\
\text { Lipunan: Isang } \\
\text { Pakikipagdiyalogo ng } \\
\text { Kritikal na Pilosopiyang } \\
\text { Pilipino sa Ang Republika } \\
\text { ni Platon }\end{array}$ & Malay & Wala & 2011 \\
\hline 35 & $\begin{array}{l}\text { Ang Hermenyutika nina } \\
\text { Schleiermacher at Dilthey } \\
\text { bilang Batayang } \\
\text { Teorerikal sa Araling } \\
\text { Pilipino }\end{array}$ & Kritike & Wala & 2011 \\
\hline 36 & $\begin{array}{l}\text { Sistematikong } \\
\text { Multilingguwalismo: } \\
\text { Lunsaran ng mas Matatag } \\
\text { na Wikang Pambansa }\end{array}$ & Malay & Wala & 2012 \\
\hline 37 & $\begin{array}{l}\text { Don Isabelo de los Reyes } \\
\text { (1864-1938): Forerunner of } \\
\text { Filipino Theology }\end{array}$ & Philippiniana Sacra & Wala & 2012 \\
\hline 38 & $\begin{array}{l}\text { Kolonisasyon at mga } \\
\text { Inuming Nakalalasing ng } \\
\text { mga Sinaunang Bisaya ng } \\
\text { Samar at Leyte }\end{array}$ & Malay & Wala & 2012 \\
\hline
\end{tabular}


108 SI DEMETERIO AT ANG PILOSOPIYANG PILIPINO

\begin{tabular}{|c|c|c|c|c|}
\hline 39 & $\begin{array}{l}\text { Ang mga Dialohikal na } \\
\text { Hermenyutika nina } \\
\text { Heidegger, Bultmann, at } \\
\text { Gadamer Bilang Batayang } \\
\text { Teoretikal sa Araling } \\
\text { Filipino }\end{array}$ & Kritike & Wala & 2012 \\
\hline 40 & $\begin{array}{l}\text { Antonio Gramsci And } \\
\text { Edward Said's Image of A } \\
\text { Modern Day Intellectual } \\
\text { and The Filipino Roman } \\
\text { Catholic Priest }\end{array}$ & Lumina & Wala & 2012 \\
\hline 41 & $\begin{array}{l}\text { Status of and Directions } \\
\text { for "Filipino Philosophy" } \\
\text { in Zialcita, Timbreza, } \\
\text { Quito, Abulad, } \\
\text { Mabaquiao, Gripaldo, and } \\
\text { Co }\end{array}$ & Philosophia & Wala & 2013 \\
\hline 42 & $\begin{array}{l}\text { Looking at Botong } \\
\text { Francisco from the } \\
\text { Horizon of Diego Rivera: } \\
\text { A Visual Dialogue } \\
\text { between Two Modern } \\
\text { Muralists }\end{array}$ & Philippiniana Sacra & Wala & 2013 \\
\hline 43 & $\begin{array}{l}\text { Ang Nobelang "Si } \\
\text { Amapola sa } 65 \text { na } \\
\text { Kabanata" ni Ricardo Lee } \\
\text { Bilang Kontra-Diskurso } \\
\text { ng Baklang Manilenyo } \\
\text { Laban sa Homopobikong } \\
\text { Kamalayang Filipino }\end{array}$ & Malay & Wala & 2013 \\
\hline 44 & $\begin{array}{l}\text { Ang Paglubog nina } \\
\text { Hippokrates at Galen sa } \\
\text { Kanluran: Isang } \\
\text { Intepretasyon sa Anyo ng } \\
\text { Siyantipikong Rebolusyon } \\
\text { sa Larangan ng Medisina }\end{array}$ & Kritike & Wala & 2013 \\
\hline 45 & $\begin{array}{l}\text { Isang Semyolohikal na } \\
\text { Pagsusuri sa mga } \\
\text { Kontradiksiyong } \\
\text { Nakapaloob sa } \\
\text { Panlipunang Kritisismo ni } \\
\text { Gloc-9 }\end{array}$ & Malay & Wala & 2013 \\
\hline 46 & $\begin{array}{l}\text { Ang Pilosopiya ni Jean- } \\
\text { Francois Lyotard bilang } \\
\text { Batayang Teoretikal sa } \\
\text { Araling Pilipino }\end{array}$ & Kritike & Wala & 2013 \\
\hline 47 & $\begin{array}{l}\text { Assessing the } \\
\text { Development Potentials of } \\
\text { some Twelve Discourses } \\
\text { of Filipino Philosophy }\end{array}$ & Philippiniana Sacra & Wala & 2014 \\
\hline 48 & $\begin{array}{l}\text { Quito, Ceniza, Timbreza, } \\
\text { Gripaldo: DLSU }\end{array}$ & Philosophia & Wala & 2014 \\
\hline
\end{tabular}

(c) 2018 Mary Irene Clare O. Deleña, Joshua Mariz B. Felicilda, and Leslie Anne L. Liwanag https://www.kritike.org/journal/issue 22/delena-felicilda-liwanag june2018.pdf ISSN 1908-7330 


\begin{tabular}{|c|c|c|c|c|}
\hline & $\begin{array}{l}\text { Professors' Contributions } \\
\text { to Filipino Philosophy }\end{array}$ & & & \\
\hline 49 & $\begin{array}{l}\text { Ang Negatibong Imahen } \\
\text { ng Maynila sa Nobelang } \\
\text { Inferno ni Dan Brown }\end{array}$ & Kritike & Wala & 2014 \\
\hline 50 & $\begin{array}{l}\text { Iris Marion Young's } \\
\text { Theory of Structural } \\
\text { Justice and Collective } \\
\text { Responsibility }\end{array}$ & Scientia & Wala & 2014 \\
\hline 51 & $\begin{array}{l}\text { Ang Pilosopiya ni Pierre } \\
\text { Bourdieu bilang Batayang } \\
\text { Teoretikal sa Araling } \\
\text { Pilipino }\end{array}$ & Kritike & $\begin{array}{l}\text { Leslie Anne } \\
\text { Liwanag }\end{array}$ & 2014 \\
\hline 52 & $\begin{array}{l}\text { Kohlbergian Analysis of } \\
\text { the Moral Reasoning in } \\
\text { Lino Brocka's Leading } \\
\text { Films }\end{array}$ & $\begin{array}{c}\text { Humanities } \\
\text { Diliman }\end{array}$ & Diana Palmes & 2015 \\
\hline 53 & $\begin{array}{l}\text { The Language Policies } \\
\text { and Practices of the } \\
\text { Philippines and Thailand: } \\
\text { Insights and Lessons for } \\
\text { Language Planning }\end{array}$ & Silliman Journal & $\begin{array}{l}\text { Leslie Anne } \\
\text { Liwanag }\end{array}$ & 2015 \\
\hline 54 & $\begin{array}{l}\text { Ang Pilosopiya ni Jean } \\
\text { Baudrillard bilang } \\
\text { Batayang Teoretikal sa } \\
\text { Araling Pilipino }\end{array}$ & Kritike & $\begin{array}{l}\text { Emmanuel de } \\
\text { Leon }\end{array}$ & 2015 \\
\hline 55 & $\begin{array}{l}\text { The Image of Japan in the } \\
\text { Philippine Periodical La } \\
\text { Solidaridad: } 1889-1895\end{array}$ & Silliman Journal & $\begin{array}{c}\text { Renato Maligaya } \\
\text { and Maria Luisa } \\
\text { Mamaradlo } \\
\end{array}$ & 2015 \\
\hline 56 & $\begin{array}{l}\text { Ang Ugnayan ng Wika, } \\
\text { Pananaliksik at } \\
\text { Internasyonalisasyong } \\
\text { Akademiko }\end{array}$ & Malay & $\begin{array}{l}\text { Joshua Mariz } \\
\text { Felicilda }\end{array}$ & 2015 \\
\hline 57 & $\begin{array}{l}\text { Isang Mapanuring } \\
\text { Paghahambing sa Ingles, } \\
\text { Filipino at Sebwanong } \\
\text { Salin ng Orihinal na } \\
\text { Espanyol na Panitik ng } \\
\text { Pambansang Awit ng } \\
\text { Pilipinas }\end{array}$ & $\begin{array}{l}\text { Humanities } \\
\text { Diliman }\end{array}$ & \begin{tabular}{|l|} 
Gem Carlo Ausa, \\
Jamie Guerrero, \\
Jianne Irissa \\
Piguing, Sofia \\
Mae Romero, and \\
Deborrah \\
Anastacio \\
\end{tabular} & 2016 \\
\hline 58 & $\begin{array}{l}\text { The Traditional Tattoos of } \\
\text { the Philippine Cordillera } \\
\text { Region: a Study on their } \\
\text { Differences in } \\
\text { Appearance, Causes and } \\
\text { Discursive Strenghts }\end{array}$ & Search & $\begin{array}{l}\text { Janette Calimag, } \\
\text { Reynele Bren } \\
\text { Zafra, and Lady } \\
\text { Aileen Ambion }\end{array}$ & 2016 \\
\hline 59 & $\begin{array}{l}\text { Barthesian Semiologies on } \\
\text { Selected YouTube Video } \\
\text { Clips of Petra } \\
\text { Mahalimuyak }\end{array}$ & Plaridel & $\begin{array}{l}\text { Leslie Anne } \\
\text { Liwanag }\end{array}$ & 2016 \\
\hline 60 & $\begin{array}{l}\text { Wika ng Manlalarong } \\
\text { Pilipino: Pagsusuri sa }\end{array}$ & $\begin{array}{c}\text { Humanities } \\
\text { Diliman }\end{array}$ & $\begin{array}{c}\text { Merwyn Abel, } \\
\text { Christian }\end{array}$ & 2016 \\
\hline
\end{tabular}




\section{SI DEMETERIO AT ANG PILOSOPIYANG PILIPINO}

\begin{tabular}{|c|c|c|c|c|}
\hline & $\begin{array}{l}\text { Pinagmulan at Saysay ng } \\
\text { mga Salitang Ginagamit } \\
\text { sa Mundo ng DotA } 2 \text { at } \\
\text { LoL }\end{array}$ & & $\begin{array}{c}\text { Autor, and } \\
\text { Aaron Gripal }\end{array}$ & \\
\hline 61 & $\begin{array}{l}\text { Sa Kanilang Naiibang } \\
\text { Pag-iindak at } \\
\text { Pamumukadkad: } \\
\text { Performativity at } \\
\text { Pagkalesbiyan sa mga } \\
\text { Indie Film na Rome and } \\
\text { Juliet at Ang Huling Cha- } \\
\text { Cha ni Anita }\end{array}$ & Kritike & $\begin{array}{c}\text { Judith Angeles, } \\
\text { Tracie } \\
\text { Kathlynne } \\
\text { Bacarro, } \\
\text { Jonathan } \\
\text { Vergara } \\
\text { Geronimo, and } \\
\text { Patricia Bettina } \\
\text { Peliño } \\
\end{array}$ & 2016 \\
\hline 62 & $\begin{array}{l}\text { A Foucauldian } \\
\text { Reexamination of the } \\
\text { Aristotelian, Aquinian, } \\
\text { and Contemporary } \\
\text { Roman Catholic Theories } \\
\text { of Hominization } \\
\end{array}$ & Philosophia & Wala & 2017 \\
\hline 63 & $\begin{array}{l}\text { Ang Dinamiks ng mga } \\
\text { Historyograpiyang } \\
\text { Nakapaloob sa mga } \\
\text { Obrang Relihiyoso- } \\
\text { Historikal ni Carlos } \\
\text { 'Botong' Francisco } \\
\end{array}$ & $\begin{array}{c}\text { Humanities } \\
\text { Diliman }\end{array}$ & Melanie Turingan & 2017 \\
\hline 64 & $\begin{array}{l}\text { The Fading Batek: } \\
\text { Problematizing the } \\
\text { Decline of Traditional } \\
\text { Tattoos in the Philippine } \\
\text { Cordillera Region }\end{array}$ & Search & Wala & 2017 \\
\hline 65 & $\begin{array}{l}\text { The Philosophy of Sr. } \\
\text { Mary John Mananzan: } \\
\text { some Contributions to } \\
\text { Filipino Philosophy }\end{array}$ & Philosophia & $\begin{array}{c}\text { Leslie Anne } \\
\text { Liwanag }\end{array}$ & 2017 \\
\hline 66 & $\begin{array}{l}\text { Kaloka, Keri, Bongga: } \\
\text { Pakahulugan at Pahiwatig } \\
\text { ng Gay Language sa mga } \\
\text { Piling Pelikula ni Vice } \\
\text { Ganda }\end{array}$ & Plaridel & $\begin{array}{l}\text { Generoso } \\
\text { Pamittan, Jr., } \\
\text { Chari Amado, } \\
\text { and Victoria } \\
\text { Amante } \\
\end{array}$ & 2017 \\
\hline 67 & $\begin{array}{l}\text { Si Madelene Sta. Maria at } \\
\text { ang Sikolohiyang Pilipino: } \\
\text { Pakikipanayam sa isa sa } \\
\text { mga Kauna-unahang } \\
\text { Iskolar na Bumatikos sa } \\
\text { Nasabing Intelektuwal na } \\
\text { Kilusan }\end{array}$ & Kritike & $\begin{array}{l}\text { Patrick James } \\
\text { Ruiz and Leslie } \\
\text { Anne Liwanag }\end{array}$ & 2017 \\
\hline
\end{tabular}

Table 1: Listahan ng mga Artikulong Nailathala ni Demeterio mula 1991 hanggang 2017

(c) 2018 Mary Irene Clare O. Deleña, Joshua Mariz B. Felicilda, and Leslie Anne L. Liwanag https://www.kritike.org/journal/issue 22/delena-felicilda-liwanag june2018.pdf 
Isinama ng mga mananaliksik ang lahat ng artikulong nakalista sa table 1 kung saan kasama ang kanyang mga mag-aaral. Kabisado nila na sa mga kolobarasyong ito kadalasang mas aktibo at substansyal ang ambag ni Demeterio-mula sa konseptuwalisasyon hanggang sa pinal na mga rebisyon ng mga nasabing artikulo. Ipinakita sa nasabing talahanayan kung paano naging mas kolaboratibo na ang pagsusulat at paglalathala ng pantas simula noong taong 2014. Ito ang naging epekto ng kanyang pagyakap sa ideya ng pilosopiyang edukasyon ni Humboldt.

Matapos basahin ng mga mananaliksik ang mga obra ni Demeterio, inuri-uri nila ito sa hindi ekslusibong paraan gamit ang sistemang ginawa ni Liwanag sa sariling mga sanaysay tungkol kina Mananzan ${ }^{23}$ at Quito. ${ }^{24}$ Kinumpuni ni Liwanag ang sistema gamit ang 16 na diskurso ng pilosopiyang Pilipinong kinalap ni Demeterio sa sanaysay na "Status of and Directions for 'Filipino Philosophy' in Zialcita, Timbreza, Quito, Abulad, Mabaquiao, Gripaldo, and Co." ${ }^{25}$ Ipinakita sa figure 1 ang orihinal na dayagram ni Demeterio at kung paano niya nakalap ang 16 na diskursong ito. ${ }^{26}$

${ }^{23}$ Tingnan ang Liwanag, "Ang Pilosopiya ni Sr. Mary Joh Mananzan, OSB," 59-62.

24 Tingnan ang Liwanag, "Ang Pilosopiya ni Emerita S. Quito," 66-67.

25 Tingnan ang Demeterio, "Status of and Directions for 'Filipino Philosophy' in Zialcita, Timbreza, Quito, Abulad, Mabaquiao, Gripaldo, and Co,” 208.

${ }^{26}$ Ibid., 191.

(C) 2018 Mary Irene Clare O. Deleña, Joshua Mariz B. Felicilda, and Leslie Anne L. Liwanag https://www.kritike.org/journal/issue 22/delena-felicilda-liwanag june2018.pdf 


\section{SI DEMETERIO AT ANG PILOSOPIYANG PILIPINO}

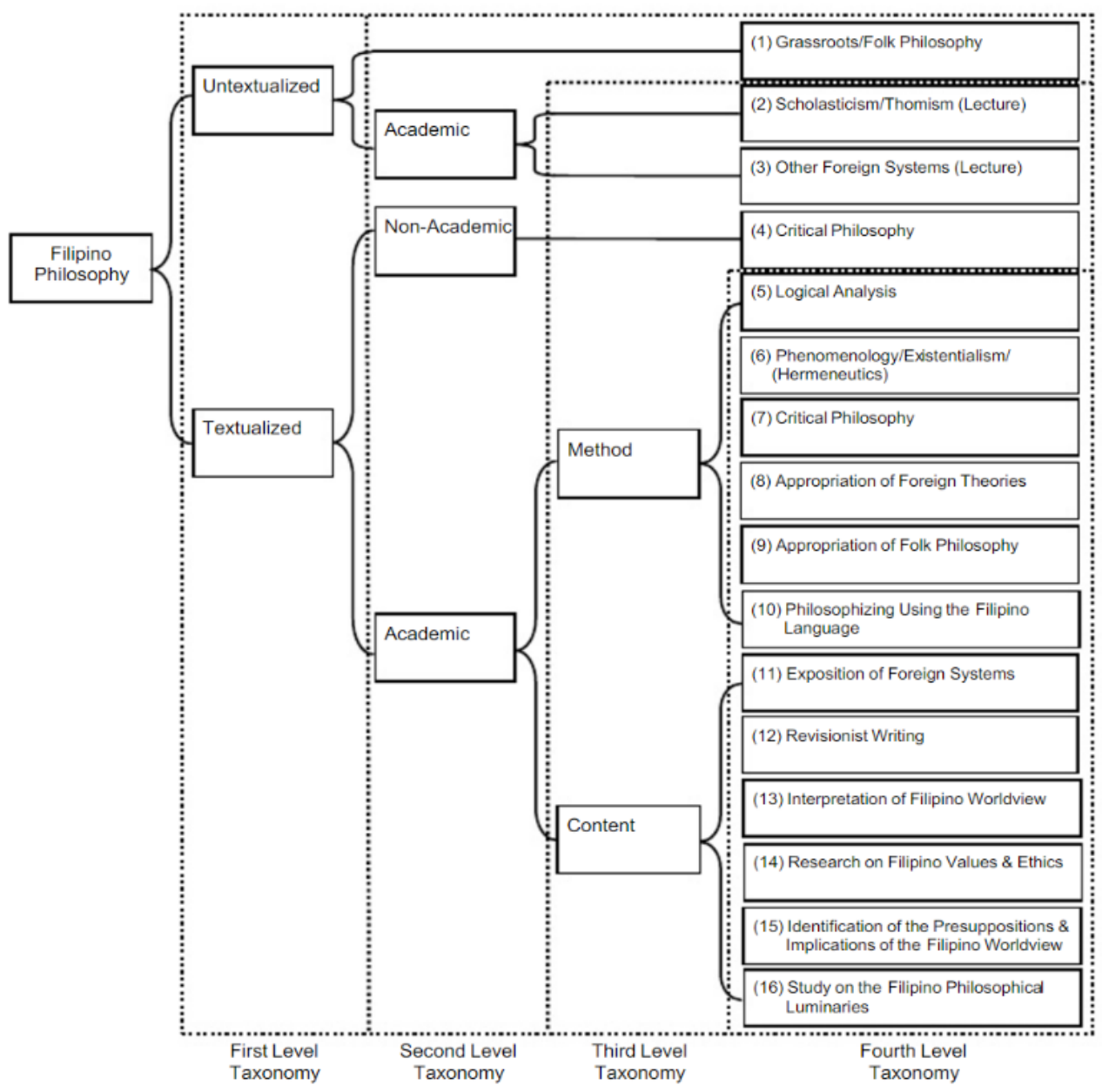

Figure 1: 16 na Diskurso ng Pilosopiyang Pilipinong Kinalap ni Demeterio at Ginamit ni Liwanag sa Pag-uri-uri ng mga Obra nina Mananzan at Quito

Mula sa 16 na diskursong kinalap ni Demeterio, isinantabi ni Liwanag ang pilosopiyang grassroot/folk sa dahilang hindi kabilang sa grassroot ang dalawang babaeng pantas na kanyang sinuri; pati na ang Iskolastisismo/Tomismo (panayam), at ibang banyagang sistema (panayam), sa dahilang mga tekstwal na dokumento ang kanyang sinuri; at pati na ang hindi akademikong kritikal na pilosopiya, sa dahilang mga akademiko ang parehong dalawang babaeng pantas na kanyang sinuri. Kaya, 12 na diskurso ng pilosopiyang Pilipino na lamang ang natira para sa sistemang kinumpuni ni Liwanag: 1) lohikal na analisis; 2) penomenolohiya, eksistensyalismo, o hermenyutika; 3) pilosopiyang kritikal; 4) pag-angkop sa mga banyagang teorya; 5) pag-angkop sa pilosopiyang grassroot o folk; 6) pamimilosopiya 
gamit ang wikang Filipino; 7) pagtalakay sa mga banyagang sistema; 8) rebisyonistang pagsusulat; 9) interpretasyon ng Pilipinong pananaw sa mundo; 10) pagsasaliksik sa Pilipinong etika at sistema ng pagpapahalaga; 11) pagsuri sa mga presuposisyon at implikasyon ng Pilipinong pananaw sa mundo; at 12) pag-aaral sa mga Pilipinong intelektwal. Ang 12 na diskurso ng pilosopiyang Pilipino ang ginamit ni Liwanag para uri-uriin ang mga obra nina Mananzan at Quito para matukoy ang hugis ng kani-kanilang mga pilosopiya at kaisipan.

Subalit para mabuo naman ang isang mas akmang sistema para sa pag-uuri-uri ng tatlong libro at mahigit 60 na artikulo ni Demeterio, minabuti ng papel na dagdagan ng dalawa pang diskurso ang 12 na diskursong pinili ni Liwanag: 1) pagmumuni sa katayuan ng pilosopiyang Pilipino, dahil sadyang marami ang nagawang obra ni Demeterio tungkol sa paksang ito; at 2) ibang hindi pilosopikal na obra, dahil bilang dalubhasa rin sa araling Pilipino, may ilang artikulo si Demeterio na hindi talaga maaaring ituring na pilosopikal.

Matapos uri-uriin ang mga obra ni Demeterio sa nasabing 14 na diskurso, ang apat na diskursong may pinakamaraming lamang obra ang ituturing na apat na diskursong higit niyang pinagtutuunan-pansin. Ang naturang apat na diskurso ang maghahayag sa hugis ng pilosopiyang Pilipinong itinataguyod ni Demeterio.

Para sa Ikalawang Substantibong Seksyon: Naglalaman ito ng transkrip ng pakikipanayam tungkol sa apat na diskurso ng pilosopiyang Pilipinong higit na pinagtutuunang-pansin ni Demeterio. Malinaw na nakaangkla ito sa unang substantibong seksyon ng papel. Matapos matukoy ang apat na diskurso ng pilosopiyang Pilipinong higit na pinagtutuunangpansin ni Demeterio, binalikan ng mga mananaliksik ang mga pangunahing obrang naiuri sa mga diskursong ito. Isinagawa ito para maihanda nila ang mga mas espesipiko at mapanuring gabay na tanong. Binalangkas ng mga mananaliksik ang pakikipanayam ayon sa apat na diskurso ng pilosopiyang Pilipinong higit na pinagtutuunan ni Demeterio. Nang kumbinsido na ang mga mananaliksik na sapat na ang mga gabay na tanong para gagapin ang lawak at lalim ng apat na diskurso ng pilosopiyang Pilipinong higit na pinagtutuunan ni Demeterio, isinagawa na nila ang pakikipanayam noong ika-13 at ika-14 ng Oktubre 2017 sa kanyang tanggapan bilang direktor ng University Research Coordination Office ng De La Salle University. 
114 SI DEMETERIO AT ANG PILOSOPIYANG PILIPINO

\section{Ang Apat na Diskurso ng Pilosopiyang Pilipinong Higit na Pinagtutuunan ni Demeterio}

Ipinakita sa table 2 kung paano inuri-uri sa hindi ekslusibong paraan ng mga mananaliksik ang tatlong libro at mahigit 60 na artikulo ni Demeterio sa 14 na diskursong binanggit na sa metodolohiya ng proyektong ito.

\begin{tabular}{|c|c|c|c|}
\hline $\begin{array}{c}\text { Diskurso ng } \\
\text { Pilosopiyang Pilipino }\end{array}$ & Pamagat ng Obra & $\begin{array}{c}\text { Bilang } \\
\text { ng mga } \\
\text { Obra }\end{array}$ & $\begin{array}{l}\text { Bahag- } \\
\text { dan }\end{array}$ \\
\hline Lohikal na Analisis & & 0 & $0.0 \%$ \\
\hline $\begin{array}{l}\text { Penomenolohiya/ } \\
\text { Eksistensyalismo/ } \\
\text { Hermenyutika }\end{array}$ & $\begin{array}{l}\text { A Comparative Study on the Theme } \\
\text { of Human Existence in the Novels of } \\
\text { Camus and Jose; Ang Hermenyutika } \\
\text { nina Schleiermacher at Dilthey } \\
\text { bilang Batayang Teorerikal sa } \\
\text { Araling Pilipino; Ang mga } \\
\text { Dialohikal na Hermenyutika nina } \\
\text { Heidegger, Bultmann, at Gadamer } \\
\text { Bilang Batayang Teoretikal sa } \\
\text { Araling Filipino; Looking at Botong } \\
\text { Francisco from the Horizon of Diego } \\
\text { Rivera: a Visual Dialogue between } \\
\text { Two Modern Muralists; Isang } \\
\text { Mapanuring Paghahambing sa } \\
\text { Ingles, Filipino at Sebwanong Salin } \\
\text { ng Orihinal na Espanyol na Panitik } \\
\text { ng Pambansang Awit ng Pilipinas; } \\
\text { and The Traditional Tattoos of the } \\
\text { Philippine Cordillera Region: a } \\
\text { Study on their Differences in } \\
\text { Appearance, Causes and Discursive } \\
\text { Strenghts }\end{array}$ & 6 & $8.6 \%$ \\
\hline Pilosopiyang Kritikal & $\begin{array}{l}\text { The Politics of Knowledge in the } \\
\text { Spanish Colonial Philippines; } \\
\text { Thought and Socio-Politics: An } \\
\text { Account of the Late 20th Century } \\
\text { Filipino Philosophy; Defining the } \\
\text { Appropriate Locus of Radical Peace } \\
\text { Studies in Filipino Philosophy; The } \\
\text { Grammar of Social Conflict in the } \\
\text { Philippine Electoral Process and the } \\
\text { Task of Filipino Philosophy; Our } \\
\text { Premodernity and their Tokens of } \\
\text { Postmodernity; The Philippine } \\
\text { Church, State, and People on the } \\
\text { Problem of Population; Some Useful } \\
\text { Lessons from Richard Rorty's } \\
\text { Pragmatism for Filipino Postcolonial } \\
\text { Discourses; Ang Balangkas Ng } \\
\text { Multikulturalismo At Ang }\end{array}$ & 31 & $44.3 \%$ \\
\hline
\end{tabular}

(C) 2018 Mary Irene Clare O. Deleña, Joshua Mariz B. Felicilda, and Leslie Anne L. Liwanag https://www.kritike.org/journal/issue 22/delena-felicilda-liwanag june2018.pdf ISSN 1908-7330 


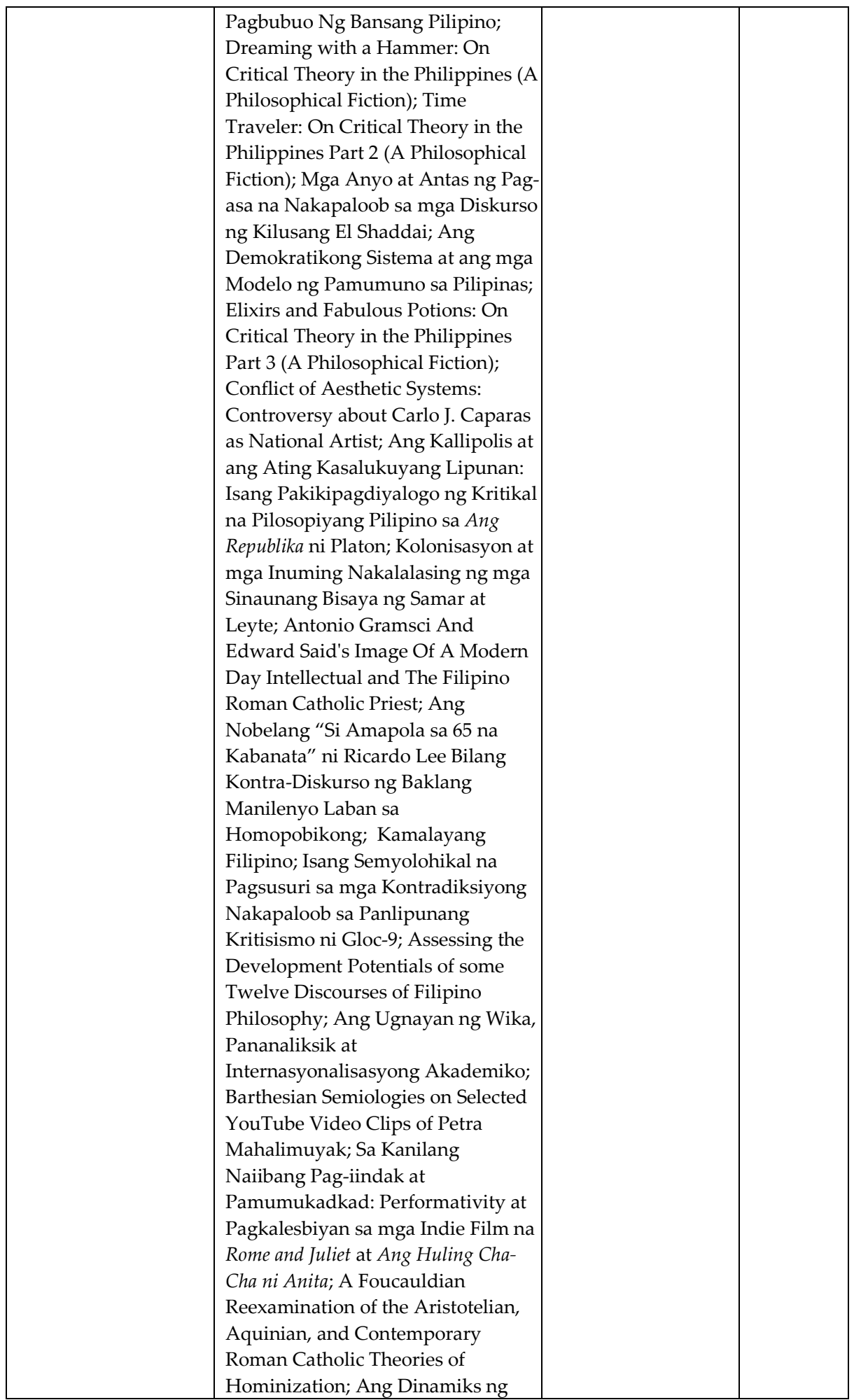

(C) 2018 Mary Irene Clare O. Deleña, Joshua Mariz B. Felicilda, and Leslie Anne L. Liwanag https://www.kritike.org/journal/issue 22/delena-felicilda-liwanag june2018.pdf 


\section{SI DEMETERIO AT ANG PILOSOPIYANG PILIPINO}

\begin{tabular}{|c|c|c|c|}
\hline & $\begin{array}{l}\text { mga Historyograpiyang } \\
\text { Nakapaloob sa mga Obrang } \\
\text { Relihiyoso-Historikal ni Carlos } \\
\text { 'Botong' Francisco; The Fading } \\
\text { Batek: Problematizing the Decline of } \\
\text { Traditional Tattoos in the Philippine } \\
\text { Cordillera Region; Kaloka, Keri, } \\
\text { Bongga: Pakahulugan at Pahiwatig } \\
\text { ng Gay Language sa mga Piling } \\
\text { Pelikula ni Vice Ganda; Si Madelene } \\
\text { Sta. Maria at ang Sikolohiyang } \\
\text { Pilipino: Pakikipanayam sa isa sa } \\
\text { mga Kauna-unahang Iskolar na } \\
\text { Bumatikos sa Nasabing } \\
\text { Intelektuwal na Kilusan; Ang mga } \\
\text { Ideolohiyang Politikal ng Catholic } \\
\text { Bishops' Conference of the Philippines: } \\
\text { isang Pag-aaral sa mga Piling Pahayag } \\
\text { mula sa Limang Panahon ng } \\
\text { Kontemporaryong Eklesiastiko-Politikal } \\
\text { na Kasaysayan ng Pilipinas; Ferdinand } \\
\text { Blumentritt and the Philippines: } \\
\text { Insights and Lessons for Contemporary } \\
\text { Philippine Studies; and The Socio- } \\
\text { Political Discourses of the Catholic } \\
\text { Bishops' Conference of the Philippines: } \\
\text { an Analysis from the Perspective of } \\
\text { Young's Theories of Structural Justice } \\
\text { and Collective Responsibility }\end{array}$ & & \\
\hline $\begin{array}{l}\text { Pag-ankop sa mga } \\
\text { Banyagang Teorya }\end{array}$ & $\begin{array}{l}\text { The Genealogy of Filipino Values; } \\
\text { The Grammar of Social Conflict in } \\
\text { the Philippine Electoral Process and } \\
\text { the Task of Filipino Philosophy; } \\
\text { Some Useful Lessons from Richard } \\
\text { Rorty's Pragmatism for Filipino } \\
\text { Postcolonial Discourses; Ang } \\
\text { Pilosopiya ni Theodor W. Adorno } \\
\text { bilang Batayang Teoretikal sa } \\
\text { Araling Pilipino; Ang Kallipolis at } \\
\text { ang Ating Kasalukuyang Lipunan: } \\
\text { Isang Pakikipagdiyalogo ng Kritikal } \\
\text { na Pilosopiyang Pilipino sa Ang } \\
\text { Republika ni Platon; Ang } \\
\text { Hermenyutika nina Schleiermacher } \\
\text { at Dilthey bilang Batayang } \\
\text { Teorerikal sa Araling Pilipino; Ang } \\
\text { mga Dialohikal na Hermenyutika } \\
\text { nina Heidegger, Bultmann, at } \\
\text { Gadamer Bilang Batayang } \\
\text { Teoretikal sa Araling Filipino; Isang } \\
\text { Semyolohikal na Pagsusuri sa mga } \\
\text { Kontradiksiyong Nakapaloob sa } \\
\text { Panlipunang Kritisismo ni Gloc-9; }\end{array}$ & 22 & $31.4 \%$ \\
\hline
\end{tabular}

(c) 2018 Mary Irene Clare O. Deleña, Joshua Mariz B. Felicilda, and Leslie Anne L. Liwanag https://www.kritike.org/journal/issue 22/delena-felicilda-liwanag june2018.pdf ISSN 1908-7330 


\begin{tabular}{|c|c|c|c|}
\hline & 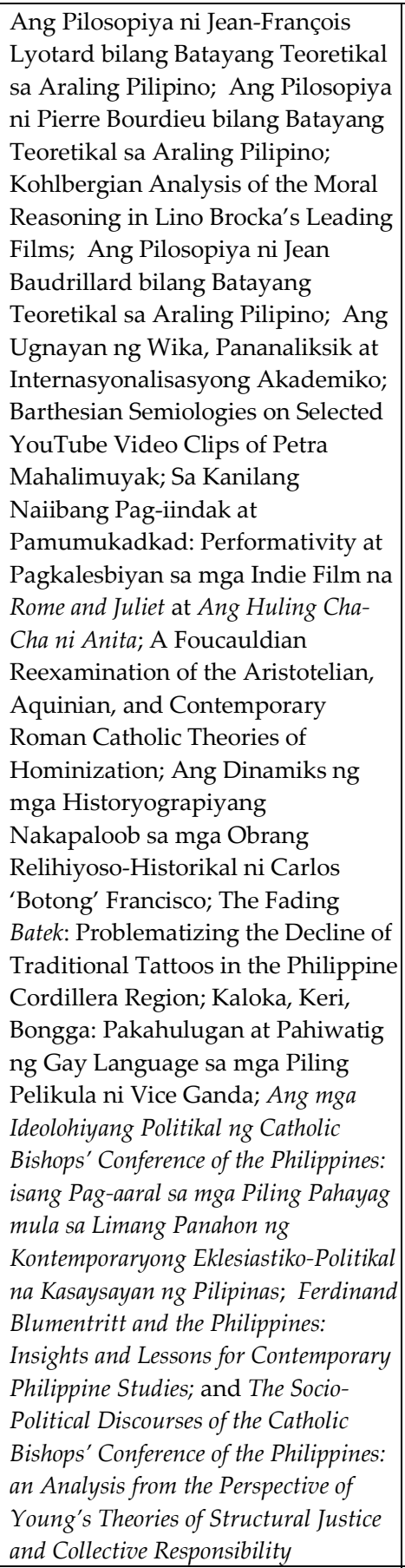 & & \\
\hline $\begin{array}{l}\text { Pag-angkop sa } \\
\text { Pilosopiyang } \\
\text { Grassroot/Folk }\end{array}$ & & 0 & $0.0 \%$ \\
\hline $\begin{array}{l}\text { Pamilosopiya Gamit } \\
\text { ang Wikang Filipino }\end{array}$ & $\begin{array}{l}\text { Ang Balangkas Ng } \\
\text { Multikulturalismo At Ang }\end{array}$ & 21 & $30.0 \%$ \\
\hline
\end{tabular}

(c) 2018 Mary Irene Clare O. Deleña, Joshua Mariz B. Felicilda, and Leslie Anne L. Liwanag https://www.kritike.org/journal/issue 22/delena-felicilda-liwanag june2018.pdf 
118 SI DEMETERIO AT ANG PILOSOPIYANG PILIPINO

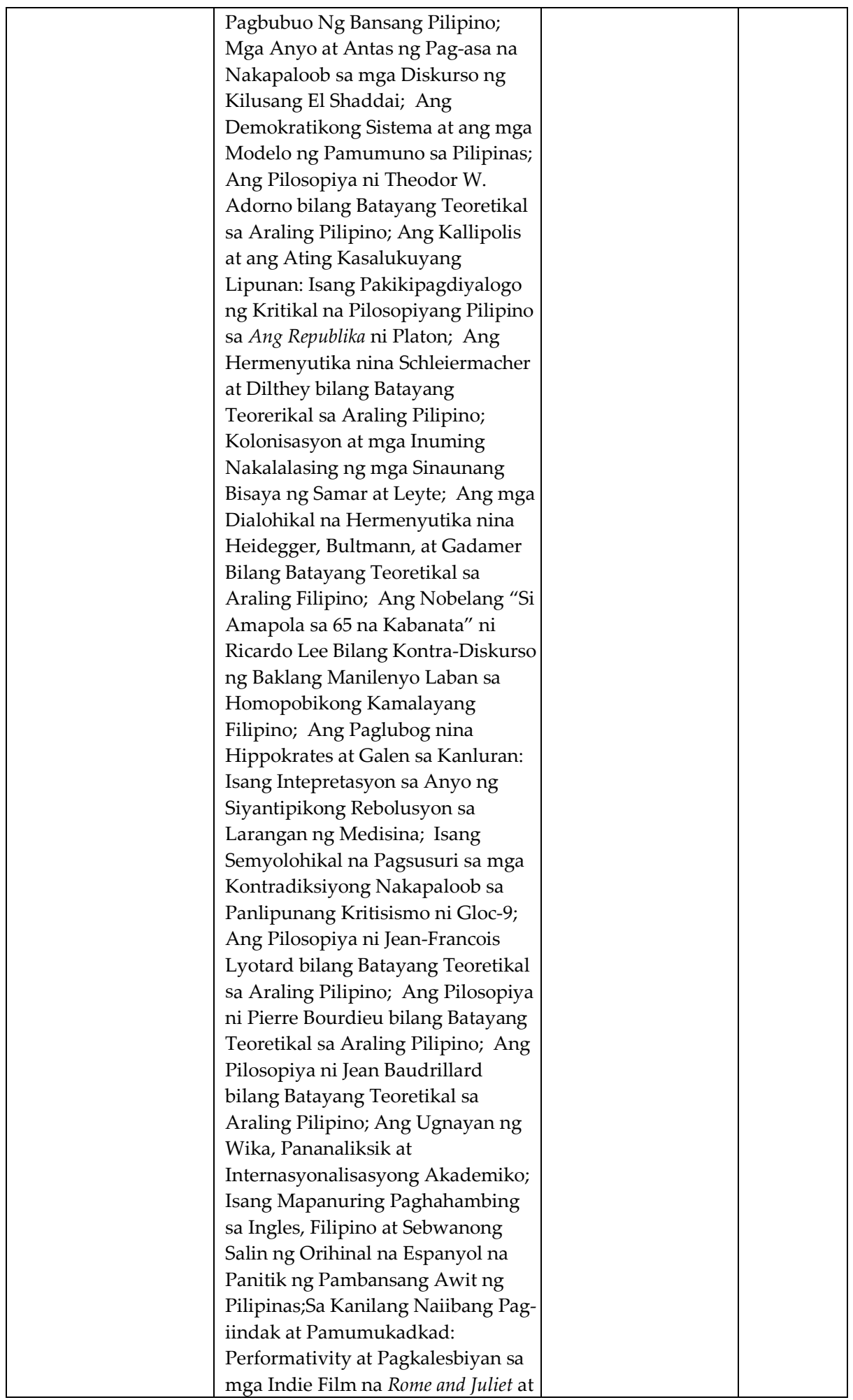

(C) 2018 Mary Irene Clare O. Deleña, Joshua Mariz B. Felicilda, and Leslie Anne L. Liwanag https://www.kritike.org/journal/issue 22/delena-felicilda-liwanag june2018.pdf 


\begin{tabular}{|c|c|c|c|}
\hline & $\begin{array}{l}\text { Ang Huling Cha-Cha ni Anita; Ang } \\
\text { Dinamiks ng mga } \\
\text { Historyograpiyang Nakapaloob sa } \\
\text { mga Obrang Relihiyoso-Historikal } \\
\text { ni Carlos 'Botong' Francisco; } \\
\text { Kaloka, Keri, Bongga: Pakahulugan } \\
\text { at Pahiwatig ng Gay Language sa } \\
\text { mga Piling Pelikula ni Vice Ganda; } \\
\text { Si Madelene Sta. Maria at ang } \\
\text { Sikolohiyang Pilipino: } \\
\text { Pakikipanayam sa isa sa mga } \\
\text { Kauna-unahang Iskolar na } \\
\text { Bumatikos sa Nasabing } \\
\text { Intelektuwal na Kilusan; and Ang } \\
\text { mga Ideolohiyang Politikal ng Catholic } \\
\text { Bishops' Conference of the Philippines: } \\
\text { isang Pag-aaral sa mga Piling Pahayag } \\
\text { mula sa Limang Panahon ng } \\
\text { Kontemporaryong Eklesiastiko-Politikal } \\
\text { na Kasaysayan ng Pilipinas }\end{array}$ & & \\
\hline $\begin{array}{l}\text { Pagtalakay sa mga } \\
\text { Banyagang Sistema }\end{array}$ & $\begin{array}{l}\text { The Platonic Undertones of Modern } \\
\text { Physics; Taking Advantage of } \\
\text { Man's Freedom or Unfreedom; A } \\
\text { Habermasian Reading of the } \\
\text { Political Philosophy Contained in } \\
\text { the Encyclical Deus Caritas Est; Ang } \\
\text { Pilosopiya ni Theodor W. Adorno } \\
\text { bilang Batayang Teoretikal sa } \\
\text { Araling Pilipino; Ang } \\
\text { Hermenyutika nina Schleiermacher } \\
\text { at Dilthey bilang Batayang } \\
\text { Teorerikal sa Araling Pilipino; Ang } \\
\text { mga Dialohikal na Hermenyutika } \\
\text { nina Heidegger, Bultmann, at } \\
\text { Gadamer Bilang Batayang } \\
\text { Teoretikal sa Araling Filipino; } \\
\text { Antonio Gramsci And Edward } \\
\text { Said's Image Of A Modern Day } \\
\text { Intellectual and The Filipino Roman } \\
\text { Catholic Priest; Ang Paglubog nina } \\
\text { Hippokrates at Galen sa Kanluran: } \\
\text { Isang Interpretasyon sa Anyo ng } \\
\text { Siyantipikong Rebolusyon sa } \\
\text { Larangan ng Medisina; Ang } \\
\text { Pilosopiya ni Jean-François Lyotard } \\
\text { bilang Batayang Teoretikal sa } \\
\text { Araling Pilipino; Iris Marion } \\
\text { Young's Theory of Structural Justice } \\
\text { and Collective Responsibility; Ang } \\
\text { Pilosopiya ni Pierre Bourdieu bilang } \\
\text { Batayang Teoretikal sa Araling } \\
\text { Pilipino; Ang Pilosopiya ni Jean } \\
\text { Baudrillard bilang Batayang }\end{array}$ & 13 & $18.6 \%$ \\
\hline
\end{tabular}




\begin{tabular}{|c|c|c|c|}
\hline & $\begin{array}{l}\text { Teoretikal sa Araling Pilipino; and } \\
\text { Ang Kallipolis at ang Ating } \\
\text { Kasalukuyang Lipunan: Isang } \\
\text { Pakikipagdiyalogo ng Kritikal na } \\
\text { Pilosopiyang Pilipino sa Ang } \\
\text { Republika ni Platon }\end{array}$ & & \\
\hline $\begin{array}{l}\text { Rebisyonistang } \\
\text { Pagsusulat }\end{array}$ & & 0 & $0.0 \%$ \\
\hline $\begin{array}{l}\text { Interpretasyon ng } \\
\text { Pilipinong Pananaw } \\
\text { sa Mundo }\end{array}$ & $\begin{array}{l}\text { Cognitive Anthropology and the } \\
\text { Unfinished Agenda of the Early } \\
\text { Indigenous Phase of Filipino } \\
\text { Philosophy; The Image and Symbol } \\
\text { of the Self in the Award-Winning } \\
\text { Filipino Novels in English; and The } \\
\text { Religious Ideology in the Award- } \\
\text { Winning Filipino Novels in English }\end{array}$ & 3 & $4.3 \%$ \\
\hline $\begin{array}{l}\text { Pagasaliksik sa } \\
\text { Pilipinong Etika at } \\
\text { Sistema ng } \\
\text { Pagpapahalaga }\end{array}$ & $\begin{array}{l}\text { The Structure of Filipino Morality; } \\
\text { The Genealogy of Filipino Values; } \\
\text { and Kohlbergian Analysis of the } \\
\text { Moral Reasoning in Lino Brocka's } \\
\text { Leading Films }\end{array}$ & 3 & $4.3 \%$ \\
\hline $\begin{array}{l}\text { Pagsuri sa mga } \\
\text { Presuposisyon at } \\
\text { Implikasyon ng } \\
\text { Pilipinong Pananaw } \\
\text { sa Mundo }\end{array}$ & & 0 & $0.0 \%$ \\
\hline $\begin{array}{l}\text { Pag-aaral sa mga } \\
\text { Pilipinong Intelektwal }\end{array}$ & $\begin{array}{l}\text { Re-Reading Emerita Quito's } \\
\text { Thoughts on the Underdevelopment } \\
\text { of Filipino Philosophy; Thomism } \\
\text { and Filipino Philosophy in the } \\
\text { Novels of Jose Rizal; A } \\
\text { Comparative Study on the Theme of } \\
\text { Human Existence in the Novels of } \\
\text { Camus and Jose; Don Isabelo de los } \\
\text { Reyes (1864-1938): Forerunner of } \\
\text { Filipino Theology; Status of and } \\
\text { Directions for "Filipino Philosophy" } \\
\text { in Zialcita, Timbreza, Quito, } \\
\text { Abulad, Mabaquiao, Gripaldo, and } \\
\text { Co; Looking at Botong Francisco } \\
\text { from the Horizon of Diego Rivera: a } \\
\text { Visual Dialogue between Two } \\
\text { Modern Muralists; Quito, Ceniza, } \\
\text { Timbreza, Gripaldo: DLSU } \\
\text { Professors' Contributions to Filipino } \\
\text { Philosophy; Kohlbergian Analysis } \\
\text { of the Moral Reasoning in Lino } \\
\text { Brocka's Leading Films; Ang } \\
\text { Dinamiks ng mga } \\
\text { Historyograpiyang Nakapaloob sa } \\
\text { mga Obrang Relihiyoso-Historikal } \\
\text { ni Carlos 'Botong' Francisco; The } \\
\text { Philosophy of Sr. Mary John }\end{array}$ & 12 & $17.1 \%$ \\
\hline
\end{tabular}

(C) 2018 Mary Irene Clare O. Deleña, Joshua Mariz B. Felicilda, and Leslie Anne L. Liwanag https://www.kritike.org/journal/issue 22/delena-felicilda-liwanag june2018.pdf ISSN 1908-7330 


\begin{tabular}{|c|c|c|c|}
\hline & $\begin{array}{l}\text { Mananzan: some Contributions to } \\
\text { Filipino Philosophy; Si Madelene } \\
\text { Sta. Maria at ang Sikolohiyang } \\
\text { Pilipino: Pakikipanayam sa isa sa } \\
\text { mga Kauna-unahang Iskolar na } \\
\text { Bumatikos sa Nasabing } \\
\text { Intelektuwal na Kilusan; and } \\
\text { Ferdinand Blumentritt and the } \\
\text { Philippines: Insights and Lessons for } \\
\text { Contemporary Philippine Studies }\end{array}$ & & \\
\hline $\begin{array}{l}\text { Pagmumuni sa } \\
\text { Katuyan ng } \\
\text { Pilosopiyang Pilipino }\end{array}$ & $\begin{array}{l}\text { Thesis Writing Guidelines for the } \\
\text { Senior Students of the Philosophy } \\
\text { Department, SBC-CAS; Re-Reading } \\
\text { Emerita Quito' Thoughts on the } \\
\text { Underdevelopment of Filipino } \\
\text { Philosophy; Cognitive } \\
\text { Anthropology and the Unfinished } \\
\text { Agenda of the Early Indigenous } \\
\text { Phase of Filipino Philosophy; } \\
\text { Thought and Socio-Politics: An } \\
\text { Account of the Late 20th Century } \\
\text { Filipino Philosophy; New } \\
\text { Paradigms for a Thesis Work in } \\
\text { Filipino Philosophy; Thomism and } \\
\text { Filipino Philosophy in the Novels of } \\
\text { Jose Rizal; Status of and Directions } \\
\text { for "Filipino Philosophy" in Zialcita, } \\
\text { Timbreza, Quito, Abulad, } \\
\text { Mabaquiao, Gripaldo, and Co; } \\
\text { Assessing the Development } \\
\text { Potentials of some Twelve } \\
\text { Discourses of Filipino Philosophy; } \\
\text { and Quito, Ceniza, Timbreza, } \\
\text { Gripaldo: DLSU Professors' } \\
\text { Contributions to Filipino } \\
\text { Philosophy }\end{array}$ & 9 & $12.9 \%$ \\
\hline $\begin{array}{l}\text { Ibang Hindi } \\
\text { Pilosopikal na Obra }\end{array}$ & $\begin{array}{l}\text { Semiology on the Invariable } \\
\text { Sacramental Elements; The } \\
\text { Rhetorical Profile of Cebuano Radio } \\
\text { Drama; The Aesthetics of Cebuano } \\
\text { Radio Drama; Ang mga Teorya ng } \\
\text { Relatividad ni Albert Einstein: Isang } \\
\text { Pagsusuri sa Kahandaan ng Wikang } \\
\text { Filipino sa Pagtatalakay sa mga } \\
\text { Paksa ng Makabagong Agham; Ang } \\
\text { Kautusan ng Departamento ng } \\
\text { Edukasyon Bilang 74, Serye 2009: } \\
\text { Isang Pagsusuri sa Katatagan ng } \\
\text { Programang Edukasyon sa Unang } \\
\text { Wika (MLE) ng Filipinas; } \\
\text { Sistematikong Multilingguwalismo: } \\
\text { Lunsaran ng mas Matatag na } \\
\text { Wikang Pambansa; Ang }\end{array}$ & 10 & $14.3 \%$ \\
\hline
\end{tabular}




\begin{tabular}{|l|l|l|l|}
\hline $\begin{array}{l}\text { Negatibong Imahen ng Maynila sa } \\
\text { Nobelang Inferno ni Dan Brown; } \\
\text { The Language Policies and Practices } \\
\text { of the Philippines and Thailand: } \\
\text { Insights and Lessons for Language } \\
\text { Planning; The Image of Japan in the } \\
\text { Philippine Periodical La Solidaridad: } \\
\text { 1889-1895; and Wika ng }\end{array}$ & $\quad$ \\
Manlalarong Pilipino: Pagsusuri sa & & \\
Pinagmulan at Saysay ng mga & & \\
Salitang Ginagamit sa Mundo ng & & \\
DotA 2 at LoL; & & \\
\hline
\end{tabular}

Table 2: Pag-uri-uri sa mga Artikulo ni Demeterio Gamit ang 12 na Diskurso ng Pilosopiyang Pilipino at Dalawa Pang Karagdagang Diskurso

Biswal na namang ipinapakita ng figure 2 ang mahahalagang impormasyong nilalaman ng table 2 .

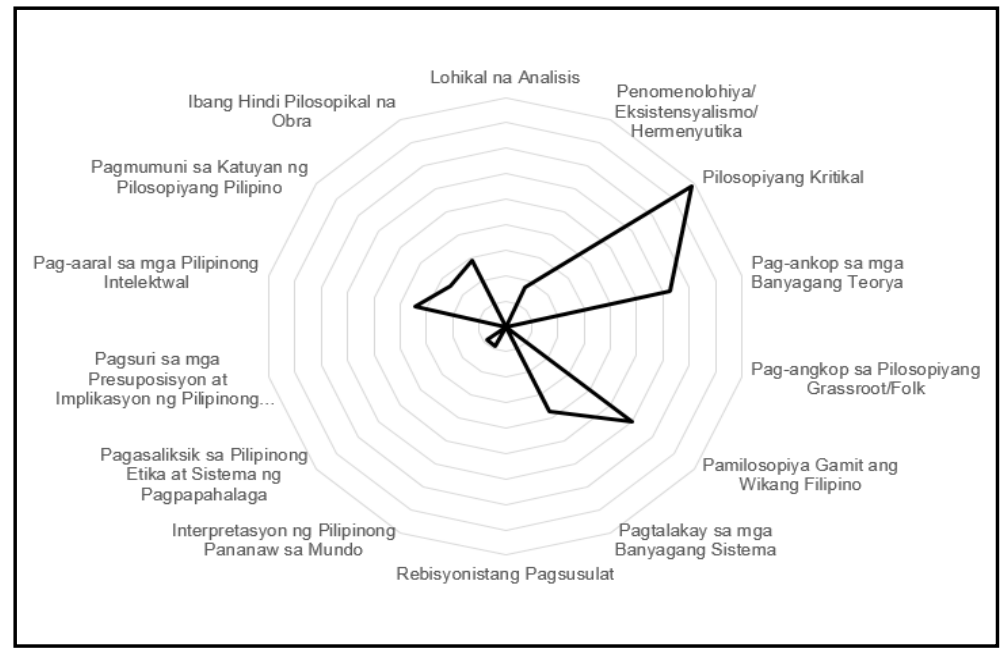

Figure 2: Radar Chart ng Pag-uri-uri sa mga Artikulo ni Demeterio Gamit ang 12 na

Diskurso ng Pilosopiyang Pilipino at Dalawa pang Karagdagang Diskurso

Ayon sa table 2 at figure 2, ang mga sumusunod ang apat na diskurso ng pilosopiyang Pilipinong higit na pinagtutuunang-pansin ni Demeterio: 1) pilosopiyang kritikal $(44.3 \%), 2)$ pag-angkop sa mga banyagang teorya $(32.4 \%)$, 3) pamimilosopiya gamit ang wikang Pilipino $(30.0 \%)$, at 4 ) pagtalakay sa mga banyagang sistema (18.6\%). Tinukoy sa "Status of and Directions for 'Filipino Philosophy' in Zialcita, Timbreza, Quito, Abulad, Mabaquiao, Gripaldo, and Co" ang kahulugan ng mga nasabing diskurso 
matapos makabuo ng komprehensibong iskema alinsunod sa mga anyo ng pilosopiyang Pilipinong binanggit ng pitong iskolar.

Ang unang diskursong pinagtutuunan ni Demeterio ay pilosopiyang kritikal. Makabuluhan ito sa konteksto ng semi-pyudal, neo-kolonyal, at burukratang-kapitalistang estado. Ito ay makapangyarihang metodo sa pamimilosopiya dahil bukas ito sa subhektibong interpretasyong magpapayabong sa mga pilosopikal na diskurso. Gayunman, panahon ng Batas Militar nang bumulusok ang mga kapaki-pakinabang na pananaliksik hinggil sa diskursong ito. Sina Zialcita, Timbreza, Quito, Mabaquiao, at Gripaldo ang mga pinagbatayang pantas ng diskursong ito.

Ang ikalawang diskursong pinagtutuunan ni Demeterio ay pagaangkop sa mga banyagang teorya. Makatuturan ang diskurso ito dahil nagbubunsod ng intelektwal na dayalogo sa pagitan ng mga pilosopikal na teoryang dayuhan at lokal na kalagayan. Gayunman, iilang Pilipinong iskolar ang nangahas sa ganitong uri ng pilosopikal na diskurso. Sina Timbreza, Quito, Abulad, at Gripaldo ang mga pinagbatayang pantas ng diskursong ito.

Ang ikatlong diskursong pinagtutuunan ni Demeterio ay ang pamimilosopiya gamit ang wikang Pilipino. Makatuturan at kapakipakinabang ang diskursong ito sapagkat naaayon sa konteksto ng karanasang Pilipino. Sa kabilang banda, natatali ang ibang iskolar sa politikal na isyu ng paggamit ng pambansang wika at limitado ang paglalathala ng ganitong pamimilosopiya sa iilang tanyag na mga abstracted journal. Sina Timbreza at Mabaquiao ang mga pinagbatayang pantas ng diskursong ito.

Ang ikaapat na diskursong pinagtutuunan ni Demeterio ay ang pagtalakay sa mga banyagang sistema. Mainam itong panimula sa pagangkop ng mga dayuhang teorya at magandang oportunidad upang suungin ang kontekstwal na pagtalakay ng mga sistemang dayuhan. Bagama't higit na maraming mga Pilipinong iskolar ang may akses sa mga Ingles na teksto, kakaunti lamang ang may kakayahang makahango ng mga arkibo ng mga partikular na pilosopo. Sina Quito, Abulad, Co, at Gripaldo ang mga pinagbatayang pantas ng diskursong ito.

Batay sa pagsusuri ng proyektong ito, isang pilosopiyang kritikal ang hugis ng pilosopiyang Pilipinong itinataguyod ni Demeterio. Bukas ito sa pag-angkop at pagtalakay ng mga kapaki-pakinabang na banyagang teorya at gumagamit ng wikang Filipino upang maipaabot ang kanyang pamimilosopiya sa mas nakararaming Pilipino.

\section{Transkrip ng Pakikipanayam}

Matapos matukoy sa naunang seksyon na nakatuon sa pilosopiyang kritikal, pag-angkop sa mga banyagang teorya, pamimilosopiya gamit ang wikang Pilipino, at pagtalakay sa mga banyagang teorya ang mga obra ni 


\section{SI DEMETERIO AT ANG PILOSOPIYANG PILIPINO}

Demeterio, isinagawa ng mga mananaliksik ang pakikipanayam noong ika13 at 14 ng Oktubre 2017 sa kanyang tanggapan sa De La Salle University. Sa bahaging ito, matutunghayan ang transkrip ng mga pakikipanayam na nakabalangkas ayon sa apat na diskurso ng pilosopiyang Pilipinong higit niyang pinagtutuunang-pansin.

\section{Tungkol sa Pilosopiyang Kritikal}

Leslie Liwanag (Kumakapanayam): Ano po ang masasabi ninyo na kasalukuyang kinikilala kayo ng ilang manunulat bilang pilosopong nagtataguyod ng kritikal na pilosopiyang Pilipino?

F.P.A. Demeterio: Naayon iyan sa karamihan na nagawa kong publikasyon, lumalabas na nakatuon ako sa kritikal na pamimilosopiya. Natutuwa ako na may ilang nakababatang pilosopo mula sa Pamantasang Santo Tomas at sa iba pang mga pamantasan ang nakapansing matingkad ang diskursong ito sa mga naisulat ko. May isa akong pananaliksik noong nagpapatunay na tumamlay ang larangang ito noong panahon ng diktaduryang Marcos. Siguro natutuwa akong makapag-ambag sa muling pagpapasigla sa nasabing larangan.

Joshua Felicilda (Kumakapanayam): Paano po kayo napunta sa larangan ng kritikal na pamimilosopiya?

Demeterio: Noong nasa Pamantasang Santo Tomas pa lamang ako, ipinakilala na sa akin ng aking mentor na si Fr. Norberto Castillo ang napakalawak at napaka-exciting na larangan ng hermenyutika. Noong nasa Unibersidad ng Pilipinas na ako, lalong napayaman ang aking interes sa hermenyutika sa neo-Marxista, postmodernista at postkolonyalistang mga teoryang tinatalakay namin. Noon, naisip naming sesentro sa kritikal na pilosopiya ang aming programang pilosopiya sa San Beda College para magkaroon ito ng malinaw na pagkakakilanlan. Kung ang Pamantasang Santo Tomas, nakabatay sa Tomismo at Iskolastisismo, ang Unibersidad ng Pilipinas sa lingguwistikong pilosopiya, ang Pamantasang Ateneo de Manila sa kontinental na mga pilosopiya, at ang Pamantasang De La Salle sa eklektisismo, pinangarap namin noong maging kilala bilang sentro ng kritikal na pamimilosopiya ang San Beda.

Mary Deleña (Kumakapanayam): Bakit po tila walang bahid ng Tomismo at Iskolastisismo ang inyong pamimilosopiya gayong produkto kayo ng pilosopiya at teolohiya ng Pamantasang Santo Tomas?

(c) 2018 Mary Irene Clare O. Deleña, Joshua Mariz B. Felicilda, and Leslie Anne L. Liwanag https://www.kritike.org/journal/issue 22/delena-felicilda-liwanag june2018.pdf ISSN 1908-7330

(c) $)$ BY-NC-ND 
Demeterio: Ang Tomismo at Iskolastisismong naranasan ko sa Pamantasang Santo Tomas ay parang katesismo, walang puwang para sa malaya at malikhaing pag-iisip. Mabuti na lamang may ilang Dominikano at paring propesor ako noong hindi masyadong nagpaalipin sa hegemonya ni Tomas Aquino. Ang mentor ko, halimbawa, tinuruan ako noon paano mag-isip nang malaya, malikhain, at walang takot. Sa halip na kabisaduhin ko si Aristoteles bilang pundasyon ng Tomismo at Iskolastisismo, si Platon ang pinabasa niya sa akin. Inilihis ang aking pag-iisip mula sa pag-iisip ng karamihang nandoon sa aming pamantasan. Isa pa, kung hindi nagsusulat ang karamihan ng mga Pilipinong Tomista, tinuruan ako ng aking mentor na dapat isinusulat at inilalathala ang malaya, malikhain, at walang takot na pag-iisip. Sa pagkaintindi ko, hindi isang institusyonal na patakaran ang katagang "publish or perish," kundi isang modo ng pamumuhay ng isang pilosopo.

Liwanag: Is there a specific text ni Platon na pinakanaka-strike sa inyo to think outside the box?

Demeterio: Timaeus ang binasa ko noon. Ito ang naging subject ng aking masteral thesis. Tungkol ito sa kosmolohiya ni Platon. Kaya mabigat sa siyensiya at matematika ang naging thesis ko. Ibang-iba ito sa mga thesis na ginawa ng mga kaklase ko. Dahil sa oras at pagod na ibinuhos ko sa thesis na iyon, naisipan kong ipagpatuloy ang aking pag-aaral sa graduate school.

Liwanag: Ano pong mga tiyak na aspekto ng kulturang Pilipino ang inyong tinutukan sa inyong mga kritikal na pagsusuri?

Demeterio: Siguro sa kasalukuyan, nakatuon ako sa edukasyon ng bansa natin; bakit tila hilaw ang ating mataas na edukasyon. Nakatuon ang ibang nagawa ko sa pananampalataya at relihiyon ng mga Pilipino. Nakatutok din ako sa malawak na erya ng kulturang popular sa Pilipinas; hinihimay ko ang mga nakakubling ideolohiya at bakas ng kolonyalismo sa ilang manipestasyon ng kulturang popular.

Felicilda: Paano po nagiging "Pilipino" ang kritikal na pamimilosopiya gayong hango pa rin ang mga teoretikal na balangkas nito sa kanluran?

Demeterio: Kahit kanluranin ang mga teoryang ginagamit natin, mapipilitan tayong iangkop at gamitin sila sa konteksto natin. Magiging dialektikal ang ugnayan ng teorya, ng pilosopong Pilipino, ng pilosopikal na problema, at ng konteksto natin. Mula sa dialektikal na prosesong ito, umaasa akong isang Pilipinong diskurso ang malilikha.

(C) 2018 Mary Irene Clare O. Deleña, Joshua Mariz B. Felicilda, and Leslie Anne L. Liwanag https://www.kritike.org/journal/issue 22/delena-felicilda-liwanag june2018.pdf 


\section{SI DEMETERIO AT ANG PILOSOPIYANG PILIPINO}

Liwanag: Ano po ang inyong masasabi sa ibang pilosopong Pilipinong walang pakialam masyado sa kritikal na pamimilosopiya?

Demeterio: Para sa akin, kanya-kanyang hilig at desisyon iyan kung sa aling larangan ng pilosopiyang Pilipino magiging komportable ang ibang pilosopong Pilipino. Ang gusto ko lamang sabihin, kahit saang larangan man mamilosopiya ang isang pilosopong Pilipino, sana maging marubdob ang kanyang pamimilosopiya at may relevance ito sa kapwa-Pilipino. Halimbawa, kapag sobrang layo na sa mundo natin ang pinagkakaabalahan ng isang pilosopong Pilipino, baka hindi pa natin kailanganin sa ngayon ang ganoong kataas na pamimilosopiya. Mas mainam para sa ating tutukan muna ang mga pilosopikal na problemang kasalukuyang bumabagabag sa atin. Hindi ko sinasabing dapat dumagsa sa larangan ng kritikal na pamimilosopiya ang lahat.

Liwanag: Aling larangan o mga larangan po ng pilosopiyang Pilipino ang sa palagay ninyong mahalagang tutukan ng ibang pilosopong Pilipino?

Demeterio: Halimbawa, nariyan ang pamimilosopiya sa larangan ng etikang Pilipino at moral na pagpapahalaga. Gusto kong mas maraming pilosopong Pilipino ang tumutok sa larangang ito dahil sa palagay ko hindi tugma ang namamayaning Kristiyanong etika sa diwang Pilipino. Kailangan nating bumuo ng isang etikang mas mabisa para sa pagpapadaloy ng kabutihangloob ng mga Pilipino. Sana huwag muna nating pag-aksayahan ng panahon iyong masyadong matataas na usaping tayo mismo hirap na magkaroon ng pananaliksik at publikasyon. Hindi kasi tamang isiping bumabagabag din sa atin bilang mga Pilipino ang mga pilosopikal na problemang bumabagabag sa mga banyagang pilosopo.

Deleña: Kadalasang pinupuna ang mga kritikal na pilosopong nakatuon lamang sa paglalathala. Sa paanong paraan po ninyo naipapamalas ang praksis ng kritikal na pamimilosopiya?

Demeterio: Para sa akin, may dalawang antas ang kritikal na pamimilosopiya: ang teoretikal na pagpuna sa kultura at lipunang Pilipino at ang praksiyohikal na pakikibaka. Mainam na parehong babad sa dalawang antas na ito ang isang pilosopong Pilipino, katulad ni Sr. Mary John Mananzan. Mas nakatutok ako sa teoretikal na antas ng pagpuna at aminado akong kulang ang aking praksis. Pero hindi ibig sabihing walang silbi na ang aking inihaing kontribusyon para sa bayan. Isa ring importanteng hakbang ang paglikha ng kritikal na kaalaman patungo sa mas malaya at makataong mundo. Bilang isang nagmamalasakit na mamamayan, sumasali ako sa ilang 
mahahalagang martsa at rally. Hindi nga lang ako organizer o speaker doon ngunit mahalaga pa rin ang aking pisikal na paglahok bilang karagdagang warm body.

Liwanag: Produkto rin po kayo ng Unibersidad ng Pilipinas, bakit hindi kayo sumanib sa mga organisasyon doon na mas nakatuon sa praksiyolohiya?

Demeterio: Sa Pamantasang Santo Tomas ko talaga naranasan ang buhaymag-aaral dahil limang diploma ang natanggap ko roon. Hindi ganoon katingkad ang politikal na pakikisangkot ng mga kapwa ko mag-aaral doon. Noong nag-aral ako sa Unibersidad ng Pilipinas, nagkaroon na ako ng trabaho at pamilya. Wala na akong pagkakataong maging bahagi sa mga ganoong organisasyon.

\section{Tungkol sa Pag-angkop ng mga Banyagang Teorya}

Liwanag: Paano po ninyo naipamamalas ang pagka-Pilipino ng isang artikulong nakasandig sa dayuhang teorya?

Demeterio: Sa palagay ko, hindi nakatali sa isang nasyonalidad ang teorya. Halimbawa na lamang si Tomas Aquino, gumagamit ng mga Griyego, Muslim, at Hudyong teorya kahit na isa siyang sarado-Katolikong pilosopo. Gamitin ang anumang katiwa-tiwalang teorya kung sa palagay nating may silbi ito sa paglutas sa pilosopikal na problemang bumabagabag sa atin.

Liwanag: Mayroon po ba tayong dapat ingatan kapag gagamit tayo ng mga dayuhang teorya sa ating sariling pamimilosopiya?

Demeterio: Bantayan lamang ang napipisil nating dayuhang teorya. Baka kasi hindi naman talaga ito angkop para sa paglutas ng kinakaharap nating problemang pilosopikal. May iba rin kasi sa ating naeengganyo masyado sa mga teorya at ipinipilit na gamitin ang mga teoryang ito kahit hindi naman talaga kailangan. Alalahanin nating laging iba ang kontekstong pinanggalingan ng isang dayuhang teorya sa konteksto natin. Kaya dapat hindi basta na lamang humihiram ng teorya. Ang proseso ng pag-aangkop ay proseso ng pagkakaroon ng ilang pagbabago sa dayuhang teorya para lalong tumugma ito sa ating sariling konteksto.

Liwanag: Ano po ang kadalasang estratehiya ninyo sa pag-angkop ng mga dayuhang teorya?

(C) 2018 Mary Irene Clare O. Deleña, Joshua Mariz B. Felicilda, and Leslie Anne L. Liwanag https://www.kritike.org/journal/issue 22/delena-felicilda-liwanag june2018.pdf 


\section{SI DEMETERIO AT ANG PILOSOPIYANG PILIPINO}

Demeterio: Karaniwang estratehiya ko ngayon ang paggamit ng wikang Filipino habang tinatalakay ang anumang dayuhang teorya. Kapag gamit mo na ang wikang Filipino, mas nagiging malay ka sarili nating konteksto. Isa palang proseso ng paghatak sa sarili nating konteksto ang akala nating simpleng pagsasalin lamang.

Liwanag: Sa proseso ng pag-aangkop, binabago po ba ang teorya mula sa pagiging dayuhan patungo sa pagiging Pilipino?

Demeterio: Isang hakbang ang pag-aangkop upang maisa-Pilipino ang isang dayuhang teorya. Kapag ipinataw mo na sa isang pilosopikal na problemang bumabagabag sa isang pilosopong Pilipino ang dayuhang teorya, lalong nagiging Pilipino ang diskursong nalilikha ng nasabing pagpataw. Kapag may iba pang pilosopong Pilipinong sususog o babatikos sa nasabing diskurso, higit na nagiging Pilipino ang panibagong diskursong nalilikha.

Liwanag: Ano ang nakikita niyong magandang nagawa ng mga naisulat niyong artikulong may pag-angkop sa mga banyagang teorya?

Demeterio: Magagamit ang mga ito bilang mga modelo para sa aking mga mag-aaral na may balak gumawa ng mga kahalintulad na proyekto. Mapapadali ang kanilang isinusulat na term paper, tesis, o disertasyon dahil sa mga ito.

Liwanag: Ano ang nakikita niyong problematikong bahagi ng mga naisulat niyong artikulong may pag-angkop sa mga banyagang teorya?

Demeterio: Wala akong naranasang problema, liban lamang na marami sa mga banyagang teoryang ito ang hindi talaga madaling intindihin. May ilang dalubhasa rin sa Araling Filipino ang nagsasabing hindi tayo dapat sumandal sa mga banyagang teoryang ito. Pero sa pamamagitan ng mga peer-reviewed na publikasyon ko, napatunayan kong posible at nakatutulong ang kritikal na paggamit ng mga ito.

Liwanag: Paano po ninyo pinipili ang mga banyagang teoryang inaangkop sa inyong pamimilosopiya?

Demeterio: Habang tuloy-tuloy akong nagbabasa, nagsusulat, at nakikipagsapalaran kaharap ang mga problemang pilosopikal at ilang banyagang teorya, lumalawak ang aking kaalaman tungkol sa mga teorya at tumatalas ang pagtatantiya ko kung aling teorya ang pinakatugma sa isang partikular na problemang pilosopikal. Parang pagpipinta o pagluluto ang 
pamimilosopiya. Maraming pagkakataong gagamitin at gagamitin mo ang iyong pakiramdam kung tama ba ang iyong pagtimpla at timing. Mahirap iarticulate ito pero habang tumatagal ang isang pintor at isang kusinero sa kanilang pagpipinta at pagluluto, lumalawak ang kanilang kaalaman tungkol sa mga materyales at sangkap. Kalaunang makakabisado na nila kung kailan at paano ang mga ito gagamitin.

\section{Tungkol sa Pamimilosopiyang Gamit ang Wikang Filipino}

Felicilda: Bakit po ninyo ginamit ang wikang Filipino sa pamimilosopiya?

Demeterio: Siguro, maraming dahilan kung bakit ko ginagamit ang wikang Filipino. Sa antas ng pilosopikal na lecture o panayam, matagal ko nang nalamang mas magandang gamitin ang wikang Filipino kasi mas buhay at mainit ang interaksyon ng guro at mag-aaral. Mas naiintindihan kasi ng magaaral ang sinasabi ng guro at hindi sila mag-aatubili o mahihiyang magtanong at magpahayag ng kanilang iniisip. Una ko itong napansin noong late 1990s at early 2000 noong nagtuturo pa ako sa Mindoro. Sa antas ng pagsusulat at pamimilosopiya sa wikang Filipino, natutunan ko ito sa Pamantasang De La Salle noong kinupkop ako ng Departamento ng Filipino. Mas madali ang pagsusulat kapag ginagamit ko ang wikang Filipino. Ayon sa Academia.edu page ko, mas binabasa ng mga kapwa nating Pilipino ang aking mga pilosopikal na artikulo kapag nakasulat ito sa wikang Filipino. Kakaunti lamang ang nagbabasa sa aking mga artikulong nakasulat sa wikang Ingles.

Felicilda: Wala po bang kabalintunaan ang pagiging isang Sebwano ninyo sa paggamit ng wikang Filipino?

Demeterio: Sa palagay ko, mas malaki ang kabalintunaan kapag isa kang dalubhasa sa pilosopiyang Pilipino pero nagsusulat ka gamit ang wikang Ingles. Sebwano ang aking unang wika, ngunit sinusubukan ko at pinipilit kong gamitin ang wikang Filipino. Humugot ako ng inspirasyon mula sa Kapampangang si Emerita Quito at mula sa Ilokanong si Florentino Timbreza. Kung kaya ng isang Kapampangan at ng isang Ilokanong mamilosopiya gamit ang wikang Filipino, kaya rin ng isang Sebwano. Alam nating may bias pa rin ang mga Sebwano laban sa wikang Filipino. Pero kaya kong sabihin sa mga kapwa ko Bisaya na maraming praktikal na bentahe ang makukuha natin kapag sa wikang Filipino tayo magsusulat at mamimilosopiya. Naalala ko ang isang isinulat ni Brother Andrew Gonzalez kung saan sinabi niyang "mas mabisa sana kung diniskurso sa antas ng

(C) 2018 Mary Irene Clare O. Deleña, Joshua Mariz B. Felicilda, and Leslie Anne L. Liwanag https://www.kritike.org/journal/issue 22/delena-felicilda-liwanag june2018.pdf 
praktikalidad kaysa antas ng pagsasabansa ang pagpapalaganap sa wikang Filipino."

Felicilda: May nabasa po ako sa isang artikulo ninyo tungkol kay Quito. Nabanggit ninyong problematiko pa ang isyu ng paggamit ng wikang Filipino dahil ‘di pa ito nakabatay sa diwa ng mga Pilipinong hindi Tagalog ang kanilang unang wika.

Demeterio: Unang-una, isinulat ko ang sanaysay na iyan noong taong 2000 pa. Ang konteksto ng pagkakasabi ko niyan noon ay reaksyon sa isinulat ni Quito na hindi umusbong ang pilosopiyang Pilipino dahil hindi natin ginagamit ang wikang Filipino. Para sa akin, masyadong eksaherado ang punto ni Quito dahil may mga pilosopo tayong kilala sa pamimilosopiyang gamit ang ibang wika tulad ni Tomas Aquino.

Felicilda: Nagbago na po ba ang inyong pananaw tungkol dito?

Demeterio: Nag-umpisa akong magsulat gamit ang wikang Filipino noong 2008 nang kupkupin ako ng Departamento ng Filipino ng Pamantasang De La Salle. Iyong binanggit mong sanaysay ko kay Quito, isinulat ko iyan noong panahong hindi pa ako nagsusulat sa wikang Filipino. Ang masasabi ko ngayon, hindi imposible para sa isang Pilipinong mamilosopiya gamit ang ibang wika, ngunit magiging mas madali at mas makabuluhan kapag mamimilosopiya siya gamit ang wikang Filipino. Kahit isa kang Bisaya, mas madali pa rin sayong kabisaduhin ang wikang Filipino kaysa kabisaduhin ang wikang Ingles. Sa kasalukuyan, patuloy akong namimilosopiya gamit ang wikang Filipino o Ingles. Pero sigurado akong kapag nasa wikang Filipino ang artikulo ko, mas binabasa ito ng mga kapwa nating Pilipino.

Liwanag: Gayong may ibang dalubhasang Pilipinong mas pinipiling magsulat sa wikang Ingles, maituturing po bang pilosopiyang Pilipino ang kanilang mga ginagawa?

Demeterio: Para sa akin, hindi dapat gawing batayan ang paggamit ng partikular na wika para masabi nating pilosopiyang Pilipino o hindi ang partikular na pamimilosopiya. Kahalintulad ito sa panitikang Pilipino; wala siguro sa atin ang may karapatang magsabing hindi dapat ituring na panitikang Pilipino ang mga nobela nina Jose Rizal, Nick Joaquin at F. Sionil Jose dahil lamang nakasulat ang mga ito sa wikang Espanyol at Ingles. Ang gusto ko lamang sabihin, mas madaling isulat at basahin ang pamimilosopiyang gumagamit ng wikang Filipino. Kapag nakasulat sa

(C) 2018 Mary Irene Clare O. Deleña, Joshua Mariz B. Felicilda, and Leslie Anne L. Liwanag https://www.kritike.org/journal/issue 22/delena-felicilda-liwanag june2018.pdf ISSN 1908-7330

(c) $)$ BY-NC-ND 
wikang Filipino ang pamimilosopiya ng isang pantas, mas dadami ang mga kapwa nating Pilipinong may kakayahang basahin ang mga ito.

Felicilda: Ano po ang mga disbentahe ng pamimilosopiyang gumagamit ng wikang Filipino?

Demeterio: Nakikita kong disbentahe ang katotohanang limitado lamang ang bilang ng mga de kalidad na journal na tumatanggap ng mga sanaysay na nakasulat sa wikang Filipino. Kapag dumami ang bilang ng mga pilosopong Pilipinong gumagamit ng wikang Filipino, natitiyak kong mapipilitang tanggapin ng ating mga journal ang mga sanaysay nila.

Felicilda: Ano-ano po ang mga bentahe ng pamimilosopiyang gumagamit ng wikang Filipino?

Demeterio: Mas madali itong isulat. Mas madali itong basahin. Mas maraming kapwa nating Pilipino ang may pagkakataong mabasa ang naisulat natin.

Felicilda: Ano po ang inyong mungkahi sa mga pilosopong nag-aalangang magsulat at mamilosopiya sa wikang Filipino?

Demeterio: Hangad ko lamang na masubukan nila minsang mag-lecture gamit ang wikang Filipino at damhin nila kung may pagkakaiba ba ang magiging interaksyon ng kanilang mga mag-aaral. Hangad ko lamang na masubukan nila minsang magsulat at mag-publish sa wikang Filipino at damhin nila kung gaano kadulas ang magiging takbo ng kanilang pagsusulat. Mahirap lang itong umpisahan, ngunit nakakatiyak akong magugustuhan nila ang pamimilosopiya gamit ang nasabing wika kapag nasimulan na.

\section{Tungkol sa Pagtalakay ng mga Banyagang Teorya}

Deleña: Hindi po ba mababang antas lamang ng pag-iisip ang pamimilosopiya sa larangan ng eksposisyon ng kung ano-anong mga kanluraning teorya?

Demeterio: Sinasabi ng karamihang mababang antas ang expository writing at expository philosophizing. Pero sa palagay ko, may halaga ang oras at pagod na inilaan ko sa ganitong uri ng pamimilosopiya. Hinahanda ko ang mga pilosopiyang tinatalakay ko para maangkop ko, ng aking mga mag-aaral, o maging ng aking mga mambabasa. Kaya nakasulat na sa wikang Filipino ang

(C) 2018 Mary Irene Clare O. Deleña, Joshua Mariz B. Felicilda, and Leslie Anne L. Liwanag https://www.kritike.org/journal/issue 22/delena-felicilda-liwanag june2018.pdf 


\section{SI DEMETERIO AT ANG PILOSOPIYANG PILIPINO}

karamihan sa aking mga bagong ekspositoryong sanaysay. Sa katunayan, may serye ako ng mga ekspositoryong sanaysay kung saan sinasabi ko ang mga posibleng pag-aangkop sa kanila. Kung si Quito, nagsusulat ng mga ekspositoryong sanaysay para labanan ang hegemonya ng Tomismo at Iskolastisismo, nagsusulat naman ako ng mga ekspositoryong sanaysay para may magamit tayong mga teorya sa ating pakikipagsapalaran sa mga problemang pilosopikal na bumabagabag sa atin.

Deleña: Ano po ang masasabi ninyo tungkol sa ilang mga pilosopong mas pinili ang mga teorya o balangkas na binubuo para sa panlokal na konteksto?

Demeterio: Nasabi ko na kaninang dapat walang nasyonalidad ang teorya. Pero bantayan natin iyong mga kontekstong pinagmumulan ng mga dayuhang teoryang ibang-iba sa konteksto natin. Maganda kung may sarili na tayong mga teoryang magagamit natin. Pero huwag nating isara ang ating pamimilosopiya sa maaaring maiambag sa atin ng mga banyagang teorya. Dapat lamang na maging maingat at masinop tayo sa pag-aangkop ng mga teoryang ito.

Deleña: Ano po ang dahilan ng pagtuon ninyo sa postmodernong teorya?

Demeterio: Nababad ako sa mga postmodernistang teorya habang nag-aaral ako ng doktorado sa Unibersidad ng Pilipinas. Karamihan sa mga napagaralan ko ang may kinalaman sa mga tagapagtaguyod rin ng kritikal na pamimilosopiya. Mga postmodernong pilosopong sina Michel Foucault, Jean-François (Lyotard), at Jean Baudrillard. Nakita ko ang malaking potensiyal na magamit ang kanilang mga teorya para tugunan ang ating sariling mga problemang pilosopikal.

Deleña: Nabanggit po sa isa ninyong sanaysay na hindi pa isang postmodernong bansa ang Pilipinas at nasa pre-modernong antas pa lamang ang maraming aspekto nito. Tama po ba kung ipipilit pa rin nating gamitin ang mga postmodernong teorya?

Demeterio: Dahil wala pa tayo sa postmodernong antas at pre-moderno pa ang karamihan sa mga aspekto ng lipunan natin, maraming elemento ang mga teoryang ito na malayo sa reyalidad natin. Noong nag-aral ako ng teoryang kritikal sa Univerity of London noong nakalipas na tag-araw, napansin ko kung gaano ka-high altitude ang kritikal na pamimilosopiya nila. Ground-level philosophizing ang sa tingin kong kailangan natin dito sa Pilipinas. Pero sigurado akong maraming elemento ang mga postmodernong teoryang madali nating maaangkop para sa sarili nating konteksto bilang

(C) 2018 Mary Irene Clare O. Deleña, Joshua Mariz B. Felicilda, and Leslie Anne L. Liwanag https://www.kritike.org/journal/issue 22/delena-felicilda-liwanag june2018.pdf ISSN 1908-7330

(c) $)$ BY-NC-ND 
isang bansang naghahangad maging moderno. Sa katunayan, isinulat ko na noon kung ano ang mga teorya ng postmodernismong maaaring magbigay sa atin ng mga aral at gabay kung anong uring modernidad ang dapat nating pangarapin.

Deleña: Ano po ang mga bentahe sa paggamit ng mga postmodernong teorya?

Demeterio: Interesado ako sa kritikal na talas ng mga postmodernong teorya. Ang mga ito ang gusto kong maiangkop.

Deleña: Bakit po ninyo isinusulong ang mga kolaboratibong proyekto sa pilosopiya?

Demeterio: Bilang isang research manager ng Pamatasang De La Salle, natuklasan ko ang ideya ng research university ni Wilhelm von Humboldt. 200 years old na ang ideyang ito ngunit wala pa rin tayong ganitong konsepto sa Pilipinas. Parehong hindi pa ganap na research university ang Unibersidad ng Pilipinas at ang Pamantasan ng De La Salle. Ito ang dahilan kung bakit mahina ang siyensiya, teknolohiya, at pilosopiya sa ating bansa. Kulang ang pananaliksik sa Pilipinas dahil wala tayong research university. Nalaman kong nakatungtong sa proseso ng marubdob at walang tigil na kolaborasyon sa pagitan ng mga guro at mag-aaral ang isang research university. Kaya naisip ko, habang hindi pa ganap ang pagiging research university ng Pamantasang De La Salle, maaari na akong mag-asta bilang guro ng isang research university sa pamamagitan ng pagkakaroon ng tuloy-tuloy na mga kolaboratibong proyekto. Pinapabilis at pinapayaman ng mga kolaborador ko ang aking pananaliksik, habang sinasanay ko naman sila kung ano (ang) nararapat na buhay ng isang pilosopo-ang patuloy na kolaborasyon at pananaliksik.

Deleña: Ano ang pangarap ninyo (para) sa mga susunod na henerasyon ng mga pilosopong Pilipino?

Demeterio: Nag-iwan ng mga teksto ang mga nakatatandang pilosopong Pilipino. Balak ko sana silang higitan hindi lamang sa pamamagitan ng pagiwan ng mga teksto, kundi maagang pagsasanay sa mga nakababatang pilosopong Pilipinong mamilosopiya at makayanang gawin ang mga bagay na hindi ko na nagawa. Salamat sa ideya ng research university ni Humboldt. Kung kakaunti lamang ang halaga ng mga maiiwan kong teksto, nakatitiyak akong malaki ang halagang maiaambag ng mga nakababatang pilosopong ito sa pagpapaunlad ng pilosopiyang Pilipino.

(C) 2018 Mary Irene Clare O. Deleña, Joshua Mariz B. Felicilda, and Leslie Anne L. Liwanag https://www.kritike.org/journal/issue_22/delena-felicilda-liwanag june2018.pdf 


\section{SI DEMETERIO AT ANG PILOSOPIYANG PILIPINO}

\section{Kongklusyon}

Alinsunod sa malalimang pagsusuri ng proyektong ito, naisakatuparan ng una at ikalawang substantibong seksyon ng papel ang hugis, lalim, at lawak ng pilosopiyang Pilipinong itinataguyod ni Demeterio. Narito ang mga aral at kabatirang magagagap mula sa 1) pagtukoy ng mga pangunahing diskurso ng mga obra ni Demeterio, at 2) pagsasagawa ng aktuwal na pakikipanayam na ibinalangkas mula sa nadiskubreng apat na diskursong higit na pinagtutuunan-pansin ng pantas.

Una, ang mga magkakaugnay na karanasan ni Demeterio bilang mag-aaral, propesor, administrador, at mananaliksik ang naging dahilan upang taglayin ang kasalukuyang pananaw at estado ng pagiging isang pilosopong Pilipino. Malakas ang naging talab sa kanya ni Fr. Castillo bilang tagapayo upang maging malikhain at matapang sa kanyang pamimilosopiya. Katunayan, maliwanag na saklaw ng kanyang matalas na kritisismo sa lipunan ang simbahan, pamahalaan, at edukasyon. Napagyaman ang kanyang interes sa hermenyutika kaakibat ng mga natutunang neo-Marxista, postmodernista, at postkolonyalistang teorya mula sa Unibersidad ng Pilipinas. Napaigting ng pagiging isang propesor ang kahalagahan ng wikang pambansa, naging mas madali ang talakayan sa antas ng pilosopikal na panayam at naging mas malaya at madali ang pagpapahayag sa antas ng pagsusulat at pamimilosopiya. Nabuksan ang kanyang kamalayan sa kahalagahan ng kolaborasyon kasama ang mga mag-aaral nang magsimulang maging administrador ng pananaliksik sa Pamantasang De La Salle. Habang pinayayaman ng kolaborasyon ang bilang at kalidad ng kanyang mga pag-aaral, natututo naman ang mga batang mananaliksik upang makabuo ng sanaysay pampublikasyon.

Ikalawa, nabanggit ni Demeterio na tumamlay ang pilosopiyang kritikal noong rehimen ng Pangulong Ferdinand Marcos. Nang balikan ang artikulo niyang "Ang Kallipolis at ang ang Kasalukuyang Lipunan: Isang Pakikipagdiyalogo ng Kritikal na Pilosopiyang Filipino sa Ang Republika ni Platon", matatagpuan ang pagsusuri ng karanasan ng mga Pilipino sa matinding sensura ng panahong ito kaakibat ang pagsulong ng mga mitong nagtutulak ng pansariling hangarin at ilusyon ng kaunlaran. Mawawaring hindi nakatuon sa kapakanan ng bayan ang kabuoang plano ng nasabing rehimen, isang kabalintunaan ito para kay Platon na pangunahin ang kabutihan ng pangkalahatang lipunan.

Ikatlo, mahalagang banggitin ang hermenyutika bilang pinakapundasyon ni Demeterio na ipinakilala ng tagapayo at kalaunang naging paksa ng kauna-unahang nailathalang artikulo. Nagmula ang hermenyutika sa salitang Griyegong hermeneuein na nangangahulugang "gagawa ng interpretasyon" at hermeneia na may ibig sabihing "proseso ng

(C) 2018 Mary Irene Clare O. Deleña, Joshua Mariz B. Felicilda, and Leslie Anne L. Liwanag https://www.kritike.org/journal/issue 22/delena-felicilda-liwanag june2018.pdf ISSN 1908-7330

(c) BY-NC-ND 
interpretasyon." May lingguwistikong kaugnayan kay Hermes, isang masigasig na mensahero sa pagitan ng mga diyos sa Bundok Olympus at ng mga tao. Taglay niya ang pagiging bihasa sa wika ng dalawang magkabilang panig upang maipaabot ang saloobin sa parehong mortal at imortal (Demeterio $1 \mathrm{sa}$ "Ang Hermenyutika nina Schleiermacher at Dilthey bilang Batayang Teoretikal sa Araling Pilipino"). Sa paraang ito, maaaring maituring si Demeterio bilang kontemporanyong Hermes upang maipahatid ang mahalagang mensahe sa mga tagapagsulong ng Tagalog, Filipino, at Ingles - na hindi dapat maging balakid ang paggamit ng espesipikong wika upang matantiya kung pilosopiyang Pilipino ba o hindi ang isang pamimilosopiya.

Ikaapat, alinsunod dito, makikitang hindi naging balakid ang pagsusulat sa sariling wika at maging ang pangingibang-bansa upang pagyamanin ang espesipikong diskurso tulad ng pilosopiyang Pilipino. Sa katunayan, ang paglalakbay at pag-aaral sa ibang bansa ang naging susi ni Demeterio upang mas maging kritikal sa lokal na katayuan ng pilosopiya at magnilay sa sariling diskurso sa pamimilosopiya. Napansin ng pantas na napakatayog ng antas ng kritikal na pamimilosopiya sa ibang bansa, tulad ng London, at napagtantong mas kinakailangang tutukan ang mga pilosopikal na suliraning mas makabuluhan at patuloy na bumabagabag sa lipunang Pilipino.

Ikalima, makabuluhan ding itala ang nabanggit ni Demeterio tungkol sa pagka-Pilipino ng kanyang kritikal na pamimilosopiya kahit na nakasandig sa Kanluranin ang teoretikal na balangkas. Binigyang-diin ng pantas na masasaksihan sa pamamagitan ng dialektikal na ugnayan ng teorya, ng pilosopiyang Pilipino, ng pilosopikal na problema, at ng konteksto ang kalaunang pagkaluwal ng isang pilosopiyang Pilipinong diskurso. Mahalaga ang kaisipang ito bilang modelo sa pagsusuri at pagbubuo ng Pilipinong diskurso sa ibang larangan tulad ng agham pampolitika, sosyolohiya, antropolohiya, sikolohiya, at marami pang iba. Hindi malayong maatim ang pag-iral ng teoretikal na balangkas at konseptwal na balangkas na Filipino at walang masama kung magsisimula ito sa pag-aangkop ng dayuhang teorya sa lokal na kalagayan. Kinakailangan lamang na mag-ingat sa napipisil at sa paglalapat ng dayuhang teorya upang hindi magmukhang ipinipilit lamang, at alalahaning nagmula ito sa kontekstong iba sa atin.

Ikaanim, malaki ang posibilidad na magkasundo sina Demeterio at ang kasalukuyang buhay na pilosopong Pilipinong si Sr. Mananzan sa diskurso ng pilosopiyang Pilipinong higit nilang pinagtutuunang-pansin: ang pamimilosopiyang kritikal. Gayong hindi masyadong bumabad si Demeterio sa anyo ng praksis na isinusulong ni Mananzan, tulad ng pagiging aktibo sa mga rally at politikal na organisasyon, maituturing pa ring isang uri ng praksiyolohikal na pakikibaka ang itinataguyod ni Demeterio sa usapin 


\section{SI DEMETERIO AT ANG PILOSOPIYANG PILIPINO}

ng pananaliksik sa larangan ng pilosopiyang Pilipino. Pinatunayan sa artikulong "Philosophy, Methodology and Action Research" ang dalawang nagkakaisang proseso ng praksis: isang pagtamo ng kaalaman kung ano ang mainam; at isang pag-alam kung paano ito mapakikinabangan sa mga partikular na sitwasyon. ${ }^{27}$ Sa kaso ng larangan ng pilosopiyang Pilipino, hindi maikakailang mainam at napapanahon ang pag-angkla ni Demeterio sa konsepto ng research university ni Humboldt. Sa pamamagitan ng paglalaan ng panahon sa kolaborasyon, napayayaman ang mga tekstwal na proyekto, maagang nasasanay ang mga nakababata sa pamimilosopiya at paglimbag, at nagdudulot ng insipirasyon sa iba pang guro at mag-aaral na ipagpatuloy ang paglalathala. Mapakikinabangan ito hindi lamang ng napakabatang larangan ng pilosopiyang Pilipino, datapwat maging ng susunod na henerasyon upang maging mas kritikal at matalinong mga mamamayan.

Ikapito, maaaring hindi magkasundo sa usapin ng paggamit ng dayuhang teorya sina Demeterio at ang itinuturing na tagapagtatag ng ideya ng Pantayong Pananaw na si Zeus Salazar. Pundamental kay Salazar ang pagwawaksi ng mga namamayaning Euro-Amerikanong diskursong nagpupumilit ipaliwanag kung ano at sino ang Pilipino. Umusbong ang Pantayong Pananaw dulot ng laganap na pag-angkla ng mga Pilipinong intelektwal sa mga namamayaning Euro-Amerikanong teorya. Pati na rin ang banayad at hindi malay na layunin ng ibang mga Pilipinong intelektwal na makatawag-pansin ng mga mambabasang Ingles. Sa kabilang dako, isang progresibong kabatiran ang ibinigay ni Demeterio nang ibinahagi ang mga puntos sa proseso ng pag-aangkop ng mga dayuhang teorya: 1 ) hindi nakatali sa isang nasyonalidad ang teorya, 2) hindi maiiwasan ang kontekstwalisasyon sa paggamit nito, 3) magtutulak ito sa pagsasa-Pilipino ng dayuhang teorya, at 4) kalaunang makalilikha ng Pilipinong diskurso.

Ikawalo, ipinagtibay ng pakikipanayam kay Demeterio ang teorya ng pagsasalin bilang ideolohikal na gawain at nag-uudyok ng utopikong pangarap. Sang-ayon sa teoresistang Amerikanong si Lawrence Venuti, laging ideolohikal ang pagsasalin dahil isa itong ideolohikal na pagpapasya para sa lingguwistika at kultural na kaibahan ng lokal at dayuhang teksto. Buhat nito, isa ring lunsaran ang pagsasalin upang magkaroon ng pangkalahatang pagkakaunawa sa pagitan ng dayuhan at domestikong kultura ng mga tekstong pampanitikan, mapa-elit man o masa. ${ }^{28}$ Karaniwang estilo ni Demeterio ang paggamit ng wikang pambansa upang talakayin ang anumang dayuhang teorya. Isang paraan ang malalimang pagbabasa ng Kanluraning kaisipan (simulaang lengguwahe) upang maisalin sa wikang

\footnotetext{
27 Wilfred Carr, "Philosophy, Methodology and Action Research," in Journal of Philosophy of Education, 40:4 (2006), 425.

${ }^{28}$ Lawrence Venuti, "Translation, Community, Utopia," in The Translation Studies Reader, ed. by Lawrence Venuti (London and New York: Routledge, 2000), 468.
}

(c) 2018 Mary Irene Clare O. Deleña, Joshua Mariz B. Felicilda, and Leslie Anne L. Liwanag https://www.kritike.org/journal/issue 22/delena-felicilda-liwanag june2018.pdf ISSN 1908-7330

(c) BY-NC-ND 
Filipino (tunguhang lengguwahe) at mabuksan ang kamalayan sa sariling konteksto ng maraming mambabasang Pilipino.

Higit sa lahat, ebidente sa hanay ng mga pananaliksik ni Demeterio ang layuning maisulong ang Araling Filipino alinsunod sa pagpapakahulugan ng kritikong pampanitikan at teoresistang si Priscelina Patajo-Legasto. Ayon sa kanya, hindi na nararapat pang alalahanin kung Pilipino ba o hindi ang nananaliksik na iskolar hinggil sa Pilipinas o kung gumagamit ba siya ng mga katutubong teoretikal na balangkas; maituturing itong Araling Filipino hangga't pursigidong makapag-ambag ng mga paglalarawan, interpretasyon, at kritisismong magsusulong at magpapatatag ng bansa. ${ }^{29}$ Hindi maitatanggi ang pagkamamamayan ni Demeterio bilang Filipino, ngunit hindi rin maitatatwang susi ang bulto ng kanyang mga sanaysay upang makabuo ng mas mapanuring kaalaman, malalimang maunawaan ang lipunang Filipino, at kalaunang makamit ang mas malaya at makataong mundo.

\section{Department of Filipino, De La Salle University, Philippines Department of Philosophy, De La Salle University, Philippines Department of Liberal Arts and Behavioral Sciences, Visayas State University, Philippines}

\section{References}

Abellanosa, Rhoderick John, Local Discourse, Identity and the Search for a Filipino Philosophy: A Re-exploration through the Lens of Reynaldo Ileto," in Asian Perspectives in the Arts and Humanities, 3:1 (2013).

Abulad, Romualdo, "Pilosopiyang Pilipino, Uso Pa Ba?" (Plenary Paper presented at the $10^{\text {th }}$ Philosophical Conference, Sancta Maria Mater et Regina Seminarium, Capiz, Philippines, 2010).

Atim, Ben Carlo, “Ang Diskurso ni Feorillo Petronilo Demeterio Tungkol sa Pilosopiyang Filipino: Isang Pilosopikal na Pagtatasa" (Paper presented at the Second National Conference on Philippine Studies, Caramoan, Camarines Sur, 2016).

Bagay, Rodolfo, Jr., "Development Potentials of Undergraduate Theses in Philosophy" (M.A. Thesis, De La Salle University, 2014).

Batoon, Emmanuel, “Tracing Mercado's Anthropological Perspective (Second of Two Parts)," in Kritike: An Online Journal of Philosophy, 8:2 (2014).

${ }^{29}$ Tingnan ang Priscelina Patajo-Legasto, "Philippine Studies: Have We Gone Beyond St. Louis?" in Philippine Studies: Have We Gone Beyond St. Louis (Quezon City: University of the Philippines Press, 2008), xix.

(c) 2018 Mary Irene Clare O. Deleña, Joshua Mariz B. Felicilda, and Leslie Anne L. Liwanag https://www.kritike.org/journal/issue_22/delena-felicilda-liwanag june2018.pdf 


\section{SI DEMETERIO AT ANG PILOSOPIYANG PILIPINO}

Carr, Wilfred, "Philosophy, Methodology and Action Research," in Journal of Philosophy of Education, 40:4 (2006)

Cortez, Franz, "The Philippine Engagement with Paulo Freire," in Kritike: An Online Journal of Philosophy, 7:2 (2013).

De Joya, Preciosa Regina, "In Search of Filipino Philosophy" (Ph.D. Dissertation. National University of Singapore, 2013).

De Leon, Emmanuel, “Ang Intelektuwal na Pamana ng mga Pangunahing Tomasinong Pilosoper sa Kasaysayan ng Pamimilosopiyang Filipino: Quito, Mercado, Hornedo, Timbreza, Abulad, at Co" (Ph.D. Dissertation, University of Santo Tomas, 2017).

"Ang Pilosopiya at Pamimilosopiya ni Roque J. Ferriols, SJ: Tungo sa Isang Kritikal na Pamimilosopiyang Filipino," in Kritike: An Online Journal of Philosophy, 9:2 (2015).

Demeterio, F.P.A., Ang mga Ideolohiyang Politikal ng Catholic Bishops' Conference of the Philippines: isang Pag-aaral sa mga Piling Pahayag mula sa Limang Panahon ng Kontemporaryong Eklesiastiko-Politikal na Kasaysayan ng Pilipinas (Manila: De La Salle University Publishing House, 2012). "Assessing the Developmental Potentials of Some Twelve Discourses of Filipino Philosophy," in Philippiniana Sacra, 69:147 (May-August 2014). “Re-reading Emerita Quito's Thought Concerning the Underdevelopment of Filipino Philosophy," in Scientia: Multidisciplinary Journal of San Beda College (2000). "Status of and Directions for 'Filipino Philosophy' in Zialcita, Timbreza, Quito, Abulad, Mabaquiao, Gripaldo, and Co," in

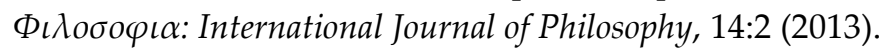
"Thomism and Filipino Philosophy in the Novels of Rizal: Rethinking the Trajectory of Filipino Thomism," in Scientia: Multidisciplinary Journal of San Beda College (2005). "Thought and Socio-Politics: An Account of the Late Twentieth Century Filipino Philosophy," in Hinogwa: The Holy Rosary Seminary Journal, 8:2 (March 2003).

Felicilda, Joshua, “Ang mga Politikal na Ideolohiyang Pumapaloob sa mga Nobela ni F. Sionil Jose" (M.A. Thesis, De La Salle University, 2017).

Geronimo, Jonathan, “Ang Karaniwang Filipino bilang Daluyan ng Diskursong Pilosopikal: Panayam kay Dr. Feorillo Petronilo A. Demeterio III," in Hasaan, 3:1 (2016).

Gripaldo, Rolando, "Filipino Philosophy: Past and Present," (Paper presented at the National Conference of the Philosophical Association of the Philippines, Ateneo de Manila University, Quezon City, 2014).

(c) 2018 Mary Irene Clare O. Deleña, Joshua Mariz B. Felicilda, and Leslie Anne L. Liwanag https://www.kritike.org/journal/issue 22/delena-felicilda-liwanag june2018.pdf ISSN 1908-7330 
Liwanag, Leslie Anne, "Ang Pilosopiya ni Emerita S. Quito," in Kritike: An Online Journal of Philosophy, 10:1 (2016).

"Ang Pilosopiya ni Sr. Mary Joh Mananzan, OSB," in Kritike: An Online Journal of Philosophy, 9:2 (2015).

Mercado, Leonardo, "Reflections on the Status of Filipino Philosophy," in Kritike: An Online Journal of Philosophy, 10:2 (2016).

Pada, Roland Theuas, "The Methodological Problems of Filipino Philosophy," in Kritike: An Online Journal of Philosophy, 8:1 (2014).

Patajo-Legasto, Priscelina "Philippine Studies: Have We Gone Beyond St. Louis?" in Philippine Studies: Have We Gone Beyond St. Louis (Quezon City: University of the Philippines Press, 2008)

Venuti, Lawrence, "Translation, Community, Utopia," in The Translation Studies Reader, ed. by Lawrence Venuti (London and New York: Routledge, 2000). 